\title{
Delimitação de unidades espaciais mínimas: uso do fluxo pendular de trabalho como primeiro passo para representação da Rede Urbana no Brasil
}

\author{
GALINDO, Ernesto Pereira ${ }^{1}$ \\ 1 Instituto de Pesquisa Econômica Aplicada, Brasil. ernesto.galindo@ipea.gov.br
}

\begin{abstract}
Resumo
A adoção de uma delimitação espacial reflete de forma direta nos resultados da análise espacial. $\mathrm{Na}$ representação da rede urbana do Brasil, o desafio é justificar uma forma específica de delimitação que corresponda a um espaço de convívio comum e a partir dele num próximo passo analisar como estes espaços se comportam. O texto objetiva neste contexto apresentar e submeter a críticas e sugestões de estudiosos e especialistas uma proposta de critério de delimitação e seu consequente resultado, tomando como unidades espaciais iniciais a serem agregados os municípios. Não há qualquer pretensão de ser uma alternativa acabada e final, nem tampouco almeja desmerecer os critérios e resultados já existentes nos mais diversos e consagrados estudos de instituições tão reconhecidas como o IBGE, o Observatório das Metrópoles, os institutos de pesquisa estaduais e mesmo o próprio Ipea. O método pretende de forma simplificada utilizar apenas um dado para determinar delimitações que representem unidades espaciais mínimas. O dado utilizado foi 0 fluxo pendular diário intermunicipal a trabalho. Uma série de justificativas é apresentada no texto para a escolha deste dado em um método que pretende ser simples sem perder a representatividade da integração territorial.
\end{abstract}

Palavras-Chave: Fluxo pendular; Rede urbana; Brasil.

\begin{abstract}
The adoption of a spatial delimitation reflects directly on the results of spatial analysis. In the representation of the urban network of Brazil, the challenge is to justify a specific form of delimitation that corresponds to a common space of convivial and from it in a next step to analyze how these spaces behave. The work aims, in this context, to present and submit to critics and suggestions of scholars and experts a proposal of delimitation criterion and its result, having as spatial units started in an agreement with the municipalities. There is no pretense of being a finished and final alternative, nor does it seek to demean the already existing criteria and results in the most diverse and sacred studies of such recognized institutions in Brazil as IBGE, the Metropolis Observatory, and research institutes as IPEA. The intended method is, in a simplified way, to use only one data to determinate delimitations that represents minimal spatial unities. The data used was the Pendulum Flow for the daily work intercity. A series of justifications and proposals is presented on the text for choosing this data in a method that pretends to be simple without losing a representation of territorial integration.
\end{abstract}

Key-Words: Pendulum flow; Urban network; Brazil. 


\section{Introdução}

Ao longo dos últimos 50 anos, desde o estudo "Divisão do Brasil em regiões funcionais urbanas", realizado pelo Instituto Brasileiro de Geografia e Estatística (IBGE) em 1966, uma série de estudos do IBGE e de outras instituições trataram de interpretar e representar a rede urbana do Brasil. Os resultados dessas configurações podem ser resumidos em três eixos (delimitação espacial contígua, relações entre essas delimitações e sua hierarquização), ainda que nem todos os estudos abordem essas três dimensões.

O primeiro destes três eixos (delimitação espacial contígua) é necessariamente a primeira etapa a ser feita. Alguns estudos não desenvolveram esta fase, por adotar uma delimitação já existente proposta por outro estudo. Essa delimitação pode ser institucional, tendo às vezes caráter oficial, incidindo deste modo sobre obrigações por parte dos entes federados envolvidos ou sobre o acesso a recursos de políticas públicas.

A adoção de uma delimitação espacial reflete de forma direta nos resultados. Como bem observado por Resende (2014), ao adotar delimitações com níveis de agregação diversos, os resultados podem ser diferentes. Deste modo, podem ser analisados os resultados i) sob vários recortes espaciais, como propôs e realizou Resende (2014) em sua abordagem multiescalar e defenderam Resende e Magalhães (2013); ii) adotar apenas um recorte existente - justificando ou não sua escolha -; ou iii) tentar desenvolver uma nova forma de delimitação. Neste último caso, espera-se uma justificativa plausível, se possível amparada por testes ou estudos de caso.

A escolha do recorte espacial se remete ao MAUP, sigla em inglês para o problema de unidade de área modificável de Oppenshaw e Taylor (1981). Em síntese indica que a definição da escala e da agregação a ser usada interfere no resultado. Oppenshaw (1983) apresenta uma forma de tentar enfrentar este problema do zoneamento automático com o uso do AZP (sigla em inglês para processo de zoneamento automático), que se inicia com a definição do núme- ro de agregações que se deseja.

Frente a estes desafios, este texto pretende dar uma contribuição ao debate, mas não se ampara nem na análise multiescalar de Resende (2014) nem na adoção do AZP de Oppenshaw (1983). O motivo é simples, a pretensão não é analisar diversos tipos de agregações e seus diferentes resultados, nem tampouco definir ad hoc uma forma de agregação com base num número de zonas (territórios ou regiões) préconcebidos. O desafio é exatamente justificar uma forma específica de delimitação que corresponda a um espaço de convívio comum e a partir dele num próximo passo analisar como estes espaços se comportam. Entende-se que num espaço de convívio comum, uma intervenção sobre alguma das unidades desagregadas impacta de forma significativa na outra e, portanto, caberia analisar e intervir sob esta perspectiva integrada.

Deste ponto de vista, a agregação por características homogêneas (como adotado no bem intencionado programa Territórios da Cidadania do governo brasileiro) não satisfaz o objetivo. Nem tampouco os resultados da divisão das microrregiões do IBGE (subdivisões das mesorregiões), pois não se tem aqui a premissa de organizar os espaços necessariamente em grupos de municípios, já que alguns demonstram fracos laços. Tampouco precisam ser respeitados os limites estaduais, já que os territórios legalmente constituídos se relacionam na prática de forma mais uma. Neste quesito tem que ser pesado no futuro a real capacidade de intervir em espaços governados por estados diferentes.

O mote aqui é a atratividade, de um ponto de vista bem específico e espera-se que suficientemente justificado. Não tem paralelo direto com as "influências" definida pelas REGICs do IBGE, que na verdade estão mais relacionadas com a fase de determinação de links da rede urbana do que com uma delimitação espacial contígua. O que mais se aproxima da intenção aqui apresentada é o recentíssimo estudo publicado pelo IBGE que desenvolveu em paralelo ao esforço do Ipea uma proposta do que foi denominado de "arranjos populacionais". 
Este documento objetiva neste contexto apresentar e submeter a críticas e sugestões de estudiosos e especialistas uma proposta de critério de delimitação e seu consequente resultado, tomando como unidades espaciais iniciais a serem agregados os municípios. Não há qualquer pretensão de ser uma alternativa acabada e final, nem tampouco almeja desmerecer os critérios e resultados já existentes nos mais diversos e consagrados estudos de instituições tão reconhecidas como o IBGE, o Observatório das Metrópoles, os institutos de pesquisa estaduais e mesmo o próprio Ipea. Cada estudo tem suas finalidades e limitações e a opção por adotar um ou outro recorte passa por critérios não apenas técnicos que resultam nas autoproclamadas regiões e territórios definidos nas políticas federais e estaduais, ou em estudos acadêmico-científicos.

O método pretende de forma simplificada utilizar apenas um dado (base para três variáveis consideradas como critério) para determinar delimitações que representem unidades espaciais mínimas, ou seja, agregações de municípios que não deveriam se encontrar separados nem na análise, nem na implementação de políticas. O dado utilizado foi o fluxo pendular diário intermunicipal a trabalho. Só é possível obter este dado nos resultados da amostra da última edição (2010) do Censo Demográfico do IBGE, pois nem no Censo de 2000 ele foi coletado exatamente desta forma (fluxo apenas a trabaIho e apenas diário). Uma série de justificativas é apresentada no texto para a escolha deste dado em um método que pretende ser simples sem perder a representatividade da integração territorial.

Aproveitando a sanção do recentíssimo Estatuto da Metrópole (Lei $n^{\circ} 13.089$, de 12 de janeiro de 2015), submete-se o resultado do método aqui proposto à configuração das regiões metropolitanas (RMs) de capitais. A intenção é demonstrar a validade e contribuição do método e apontar suas limitações no entendimento do fenômeno de coesão e integração destes supostos aglomerados urbanos. Com isso verifica-se a hipótese da possibilidade de identificação dos limites de uma RM apenas pelos fluxos pendu- lares de trabalho.

Para estruturar este documento e submetê-lo à discussão, divide-se o texto iniciando por uma seção com a justificativa do uso do fluxo pendular a trabalho, explicando na seção seguinte o método e o cálculo para delimitação espacial. É apresentada uma seção de resultados gerais e antes de realizar os testes com as RMs optouse por incluir uma seção específica com a justificativa de se testar o método com as RMs, para isso faz-se um resgate de críticas recentes sobre sua configuração. Por fim são apresentadas considerações finais abordando as contribuições e limitações do método.

\section{Por que usar o fluxo pendular de trabalho para delimitação espacial?}

O fluxo pendular intermunicipal indica o convívio de uma população num mesmo espaço durante a realização das atividades rotineiras (trabalho, estudo, saúde, lazer, cultura, etc.). Neste sentido tende a ser uma proxy para uma coesão territorial. Por sua vez, o trabalho é o principal motivo de deslocamento urbano e conforme NTU (2006) representa $52 \%$ das viagens. Conforme o Censo Demográfico 2010, 65\% das pessoas leva até meia hora no deslocamento de casa ao trabalho, chegando a $89 \%$ quando o limite é de uma hora, indicando um espaço de convívio que tende a ser limitado pelo tempo de viagem e em última instância pela distância.

De fato com a duração média de cada viagem (a qualquer motivo) de 38 minutos conforme NTU (2006) e estimativa conforme ANTP (2014) de 1,76 viagens por habitante por dia em média, o espaço de convívio rotineiro tem limites espaciais. Pode-se considerar neste aspecto que o trajeto casa-trabalho e as proximidades tanto de casa quanto do trabalho definam em boa parte o limite das outras atividades do dia a dia. Esses fluxos são por fim a identificação da força do relacionamento entre municípios em princípio contíguos.

O uso do deslocamento pendular, ainda que não seja em grande medida usado na determinação da hierarquia do aglomerado urbano, é unanimemente utilizado na delimitação de "subregiões" ou mesmo de regiões de influência lato 
sensu. Moura et al. (2013) levam o uso ao extremo e determinam tipologias hierarquizadas com base principalmente no fluxo pendular, sendo este considerado "a dimensão que mais expressa a ideia de integração".

O estudo de Moura et al. (2013) destaca uma alteração significativa no fluxo pendular de 2000 para 2010. Os fluxos de destino (ou de entrada) em 2010 totalizavam 13,9 milhões de pessoas, contra 7,0 milhões em 2000; correspondiam a $6,7 \%$, em 2000 , e $10,6 \%$, em 2010 , do total de pessoas ocupadas ou estudando, no caso das saídas, e 6,4\% e 9,6\%, respectivamente, no das entradas. Ao abordar a macrometrópole paulista, CUNHA et al. (2013, p. 434), corrobora este cenário:

Nos últimos dez anos, enquanto a taxa de crescimento anual da população das regiões metropolitanas paulistas foi de 1,1\%, a taxa de crescimento dos movimentos pendulares entre as regiões que compõem a Macrometrópole Paulista foi de 8,7\% ao ano.

IBGE (2015) cita a importância do fluxo pendular na definição territorial adotada por institutos de estatística de alguns países:

1. Na França, o Institut National de la Statistique et des Études Économiques (Insee) utiliza como uma das duas abordagens de classificação para o censo os deslocamentos para trabalho e estudo entre unidades político-administrativas (JULIEN, 2000)

2. Nos Estados Unidos, o U.S. Census Bureau ao considerar metro e microáreas como espaços que agrupam "counties" com alto nível de integração social e econômica, mensura essa integração pelo fluxo pendular de trabalho que se destina ao núcleo urbano dessas áreas (METROPOLITAN, 2013)

3. No México, o Instituto Nacional de Estadística y Geografia (Inegi) estima a porcentagem da população que vai trabalhar de um município ao outro com base nos dados da residência da população de cada município e do contingente de trabalhadores em cada um, com isso defina a que núcleo e zona metropolitana cada um está ligado.

Na França também foram desenvolvidas outras formas de regionalização com base em proxies do fluxo pendular, para identificar as "bacias" de vida e as zonas de emprego. Em que pese o fato de o território francês ser menor do que o Estado da Bahia, ele tem unidades mínimas muito subdivididas. As 36,7 mil "comunas" davam origem a 304 regiões (ou zonas de emprego) e a 1,7 mil bacias de vida. Guardadas as proporções, consideram-se conceitos de grande valia na justificativa de uso do fluxo pendular como determinante de regionalizações.

Tempos atrás para definição dessas bacias o governo francês se valia de dados sobre a frequência de cidadãos a equipamentos de serviços, mas desde que deixou de se ter esses dados, o governo necessita fazer algumas inferências relacionadas ao uso dos equipamentos por residentes de outras comunas. Atualmente, na Bacia de Vida francesa, há uma definição prévia de tipos e número de serviços que deveriam servir a uma determinada população, que pode estar em comunas sem esses serviços e a distâncias em tempo de deslocamento no horário de pico compatíveis com o uso dos equipamentos providos. No método francês se aplicam iterações até que se obtenha um resultado satisfatório e sem alterações. No caso das zonas (ou regiões) de trabalho (ou emprego) ${ }^{1}$ usa-se o Censo Francês de 2006 para saber o fluxo pendular relacionado ao trabalho de modo que a "zone d'emploi" seja um espaço geográfico dentro do qual a maior parte da PEA vive e trabalha e as empresas podem encontrar a mão de obra essencial para ocupar os empregos oferecidos.

A Empresa Paulista de Planejamento Metropolitano (EMPLASA) empregou os dados do Censo Demográfico 2010 para desenvolver estudo para a atualização da morfologia e hierarquia funcional da rede urbana paulista e para a regionalização do Estado de São Paulo, para fins de planejamento (EMPLASA, 2011). O estudo considerou como um dos critérios complementares os fluxos pendulares recebidos. Em estudo de Castello Branco (2003, p.128) também considera-se importância do fluxo pendular ao

\footnotetext{
${ }^{1}$ Disponível em:

$<$ http://www.insee.fr/fr/methodes/default.asp?page=definitions/ zone-emploi.htm> Acesso em: 20 outubro 2016.
} 
indicar que a delimitação por ela proposta era preliminar e deveria ser complementada, entre outros, com dados de deslocamento para trabaIho ou estudo. O Observatório das Metrópoles (Ribeiro, 2009) para confirmar suas hipóteses, também recomendou como imprescindível a análise do movimento pendular, cuja densidade de fluxos contribui para identificar "complexos urbanos", formados por regiões metropolitanas, aglomerações e centros urbanos.

Destaca-se que o fluxo pendular foi comumente usado como critério na definição de unidades espaciais. Castello Branco, Pereira e Nadalin (2013) destacam estudos que buscavam identificar aglomerações urbanas, com ênfase no uso da informação sobre movimentos pendulares. Na metodologia de Galvão et al. (1969), a incorporação de outros municípios à RM dependia da condição de o município atender a pelo menos um entre quatro critérios, sendo que um desses diz respeito ao nível de integração entre municípios por deslocamentos pendulares. Para os autores, um município "A" poderia ser incorporado a uma RM "caso o volume total de seus residentes que se deslocam diariamente para trabalhar em outros municípios da região somados aos moradores da região que se deslocam para trabalhar em "A" correspondam a pelo menos $10 \%$ da população total residente em "A". A incorporação dos dados de fluxo pendular como medida de integração entre cidades é um ponto comum em diversas metodologias de delimitação de RMs (Soares, 1968; Monteiro, 1968; Freeman e Cheshire, 2006; Moura et al., 2007; Casado-Díaz e Coombes, 2011; Ojima, 2011; OCDE, 2012). A definição do patamar mínimo de deslocamentos, contudo, costuma ser feita ad hoc variando de $10 \%$ a $20 \%$, seguindo diferentes formas de cálculo. (Castello Branco, Pereira e Nadalin, 2013, p.15)

O citado estudo adotou como único critério da dimensão "integração" para estimação das RMs em 2010, adaptado a partir da proposta original de Galvão et al. (1969), "pelo menos $10 \%$ da população municipal total deslocando-se diariamente, em viagens intermunicipais, para qualquer município da área (considerando fluxos de entrada e de saída do município)". Os critérios adotados no estudo citado está na tabela 1.

Tabela 1: Critérios para estimação das RMs em 2010.

\begin{tabular}{|c|c|c|}
\hline Dimensão & $\begin{array}{l}\text { Critério originalmente proposto por Galvão et al. } \\
\text { (1969) }\end{array}$ & Critérios utilizados \\
\hline \multirow{4}{*}{$\begin{array}{l}\text { (I) } \\
\text { Demográfi- } \\
\text { ca }\end{array}$} & $\begin{array}{l}\text { 1. População municipal de pelo menos } 400 \text { mil habitan- } \\
\text { tes }\end{array}$ & Mantido \\
\hline & $\begin{array}{l}\text { 2. Densidade do distrito sede de pelo menos } 500 \\
\text { hab./ } / \mathrm{km}^{2}\end{array}$ & Mantido \\
\hline & 3. Densidade municipal de pelo menos 60 hab. $/ \mathrm{km}^{2}$ & $\begin{array}{llllll}\begin{array}{l}\text { Densidade municipal de pelo menos } 60 \\
\text { hab./ } / \mathrm{km}^{2}\end{array} & & & & \\
\end{array}$ \\
\hline & $\begin{array}{l}\text { 4. Variação da população do decênio anterior deve ser de } \\
\text { no mínimo } 45 \% \text {, no município ou em um distrito contí- } \\
\text { guo }\end{array}$ & Descartado \\
\hline \multirow{3}{*}{$\begin{array}{l}\text { (II) } \\
\text { Estrutural }\end{array}$} & $\begin{array}{l}\text { 1. Pelo menos } 10 \% \text { da população potencialmente ativa } \\
\text { do município ocupada em atividades industriais }\end{array}$ & $\begin{array}{l}\text { Pelo menos } 70 \% \text { da sua população ocupada } \\
\text { em atividades urbanas }\end{array}$ \\
\hline & $\begin{array}{l}\text { 2. No caso dos chamados núcleos "dormitórios" esta } \\
\text { porcentagem é substituída por um índice de movimento } \\
\text { pendular, igual ou superior a } 20 \% \text { da população, deslo- } \\
\text { cando-se diariamente para qualquer município da área }\end{array}$ & Descartado \\
\hline & $\begin{array}{l}\text { 3. Quando o valor da produção industrial municipal for } \\
\text { três vezes maior que o da agrícola }\end{array}$ & Descartado \\
\hline \multirow{2}{*}{$\begin{array}{l}\text { (III) } \\
\text { Integração }\end{array}$} & $\begin{array}{l}\text { 1. Pelo menos } 10 \% \text { da população municipal total deslo- } \\
\text { cando-se diariamente, em viagens intermunicipais, para } \\
\text { qualquer município da área (considerando fluxos de } \\
\text { entrada e saída do município) }\end{array}$ & Mantido \\
\hline & $\begin{array}{l}\text { 2. Quando tiver um índice de ligações telefônicas para a } \\
\text { cidade central superior a oitenta, por aparelho, durante } \\
\text { um ano. }\end{array}$ & Descartado por indisponibilidade de dados \\
\hline
\end{tabular}

Fonte: Castello Branco, Pereira e Nadalin, 2013, p.16 
ESPON (2007) apresenta como uma das três abordagens para se analisar as áreas metropolitanas europeias a funcional, que define as áreas metropolitanas com base nas interações econômicas e nos fluxos pendulares.

Tomando de França (2013), o exemplo da Espanha observa-se que Serrano (2008) hierarquizou a rede urbana espanhola em quatro níveis, sendo um deles os deslocamentos pendulares.
Como bem relatado nas seções anteriores, o uso do fluxo pendular é unânime na determinação de sub-regiões mais coesas, em especial aqueles com forte integração como regiões metropolitanas. A tabela 2 sintetiza as informações e critérios considerados por alguns dos estudos com base na revisão presente em Galindo et al. (2015) para identificação de unidades regionais urbanas, e entre eles, percebe-se a presença constante dos movimentos pendulares, em suas várias escalas de corte.

Tabela 2: Critérios de identificação de unidades regionais urbanas, segundo estudos selecionados.

\begin{tabular}{|c|c|c|c|c|c|c|}
\hline \multirow[b]{2}{*}{$\begin{array}{l}\text { Informa- } \\
\text { ção }\end{array}$} & \multicolumn{6}{|c|}{ Autor } \\
\hline & $\begin{array}{l}\text { Galvão et al. } \\
\text { (1969) }\end{array}$ & $\begin{array}{l}\text { Davidovich e } \\
\text { Lima (1975) }\end{array}$ & $\begin{array}{l}\text { Motta } \\
(2002 a)\end{array}$ & $\begin{array}{l}\text { IBGE } \\
\text { (2008a) }\end{array}$ & $\begin{array}{l}\text { Emplasa } \\
\text { (2011) }\end{array}$ & $\begin{array}{l}\text { Castello Branco, } \\
\text { Pereira e Nadalin } \\
(2013)\end{array}$ \\
\hline \multicolumn{7}{|c|}{ Aglomerações metropolitanas } \\
\hline $\begin{array}{l}\text { População } \\
\text { do núcleo } \\
\text { central }\end{array}$ & $>=400 \mathrm{mil}$ & $>=300 \mathrm{mil}$ & $>=800 \mathrm{mil}$ & & $\begin{array}{l}>=1,5 \text { mi- } \\
\text { lhão (região) }\end{array}$ & $>=400 \mathrm{mil}$ \\
\hline $\begin{array}{l}\text { Densidade } \\
\text { (polo) }\end{array}$ & $\begin{array}{l}>=500 \text { habitan- } \\
\text { tes } / \mathrm{km} 2\end{array}$ & & & & $\begin{array}{l}>=700 \text { habi- } \\
\text { tantes } / \mathrm{km} 2 \\
\text { (região) }\end{array}$ & $\begin{array}{l}>=500 \text { habitan- } \\
\text { tes } / \mathrm{km} 2\end{array}$ \\
\hline \multicolumn{7}{|c|}{ Aglomerações não metropolitanas } \\
\hline $\begin{array}{l}\text { População } \\
\text { do núcleo } \\
\text { central }\end{array}$ & & $\begin{array}{l}>=100 \text { mil } \\
\text { (mononucle- } \\
\text { ada) } \\
>=75 \text { mil } \\
\text { (polinuclea- } \\
\text { da) }\end{array}$ & $\begin{array}{l}>=200 \text { mil } \\
\text { (mononucle- } \\
\text { ada) } \\
>=150 \text { mil } \\
\text { (polinuclea- } \\
\text { da) }\end{array}$ & & \multicolumn{2}{|c|}{$>=250$ mil (região) } \\
\hline Densidade & & & & & $>=150$ habita & ntes/km2 (região) \\
\hline \multicolumn{7}{|c|}{ Área de concentração de população } \\
\hline $\begin{array}{l}\text { População } \\
\text { do núcleo } \\
\text { central }\end{array}$ & & & & $>=350 \mathrm{mil}$ & & \\
\hline Densidade & & & & $\begin{array}{l}>=850 \text { habi- } \\
\text { tantes } / \mathrm{km} 2\end{array}$ & & \\
\hline \multicolumn{7}{|c|}{ Municípios do entorno } \\
\hline Densidade & $\begin{array}{l}\text { > } 60 \text { habitan- } \\
\text { tes/km2 ou no } \\
\text { mínimo um distrito } \\
\text { contíguo a outro } \\
\text { município }\end{array}$ & $\begin{array}{l}>60 \text { habitan- } \\
\text { tes } / \mathrm{km} 2\end{array}$ & $\begin{array}{l}>60 \text { habitan- } \\
\text { tes } / \mathrm{km} 2\end{array}$ & $\begin{array}{l}>850 \text { habi- } \\
\text { tantes } / \mathrm{km} 2\end{array}$ & & $\begin{array}{l}\text { > } 60 \text { habitan- } \\
\text { tes/km2 ou no mí- } \\
\text { nimo um distrito } \\
\text { contíguo a outro } \\
\text { município }\end{array}$ \\
\hline $\begin{array}{l}\text { Ocupação } \\
\text { (PEA) }\end{array}$ & $\begin{array}{l}\text { > } 10 \% \text { em ativida- } \\
\text { des industriais; ou } \\
\text { valor da produção } \\
\text { industrial corres- } \\
\text { pondente ao triplo } \\
\text { do valor da produ- } \\
\text { ção agrícola }\end{array}$ & $\begin{array}{l}>65 \% \text { em } \\
\text { atividades } \\
\text { urbanas } \\
\text { (secundário e } \\
\text { terciário) }\end{array}$ & $\begin{array}{l}>65 \% \text { em } \\
\text { atividades } \\
\text { urbanas } \\
\text { (secundário e } \\
\text { terciário) }\end{array}$ & $\begin{array}{l}>=81,5 \% \text { em } \\
\text { atividades } \\
\text { não agrícolas }\end{array}$ & & $\begin{array}{l}\text { Pelo menos } 70 \% \text { da } \\
\text { sua população ocu- } \\
\text { pada em > = } 70 \% \text { da } \\
\text { população ocupada } \\
\text { em atividades urba- } \\
\text { nas }\end{array}$ \\
\hline $\begin{array}{l}\text { Crescimen- } \\
\text { to da popu- } \\
\text { lação dos } \\
\text { municípios }\end{array}$ & $\begin{array}{l}>45 \% \text { no último } \\
\text { período intercensi- } \\
\text { tário }\end{array}$ & $\begin{array}{l}>45 \% \text { no } \\
\text { último perío- } \\
\text { do intercensi- } \\
\text { tário }\end{array}$ & & & \multicolumn{2}{|c|}{ > = média estadual } \\
\hline
\end{tabular}




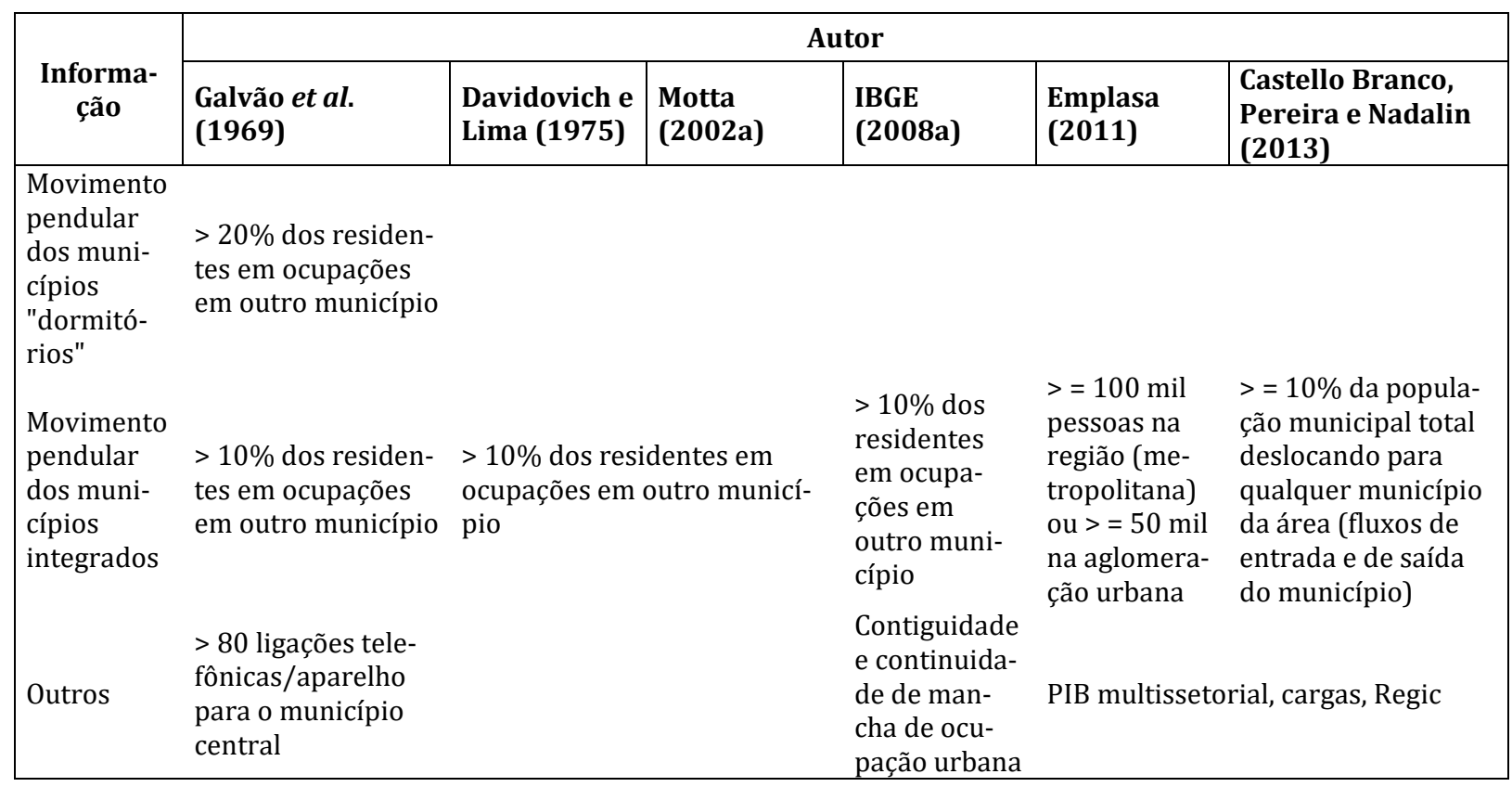

Fonte: Galindo et al. (2015).

Antes de adentrar na definição do método, cabe ressaltar que o que comumente se chama de rede urbana não deve excluir as relações "rurais". Trata-se de analisar as dinâmicas dos e entre os municípios, entendendo a acepção de "urbano" como "municipal". O próprio Estatuto da "Cidade" e o plano diretor "urbano" já são entendidos unanimemente como termos que se referem à totalidade do município e com ele as relações urbano-rural. Este ponto de partida evita que se excluam relacionamentos que identifiquem dinâmicas entre os municípios.

A partir da tebale 2 apresentada, constata-se que os outros critérios de definição das aglomerações tendem a suprimir da construção núcleos com perfis não metropolitanos e mesmo não urbanos stricto sensu. Recortes de densidade, tamanho de população ou outros indica- dores explicitamente urbanos são utilizados para, a priori, desqualificar outras situações de coesão e integração.

Buscando confirmar a importância dos fluxos pendulares nas medidas de integração entre municípios e ilustrar sua abrangência no território brasileiro, a figura 1 mostra o resultado da plotagem da proporção dos fluxos pendulares da população para trabalho e estudo em outro município que não o de residência, para todo o país, a partir de dados do Censo Demográfico de 2010, em relação ao total das pessoas do município que trabalham e estudam, sem distinguir o município de destino, e sob um critério de corte de $10 \%$. Ou seja, apenas considera fluxos pendulares superiores a $10 \%$ do total de pessoas do município que estudam e trabalham. 
Figura 1: Movimento pendular para trabalho e ou estudo - Brasil 2010

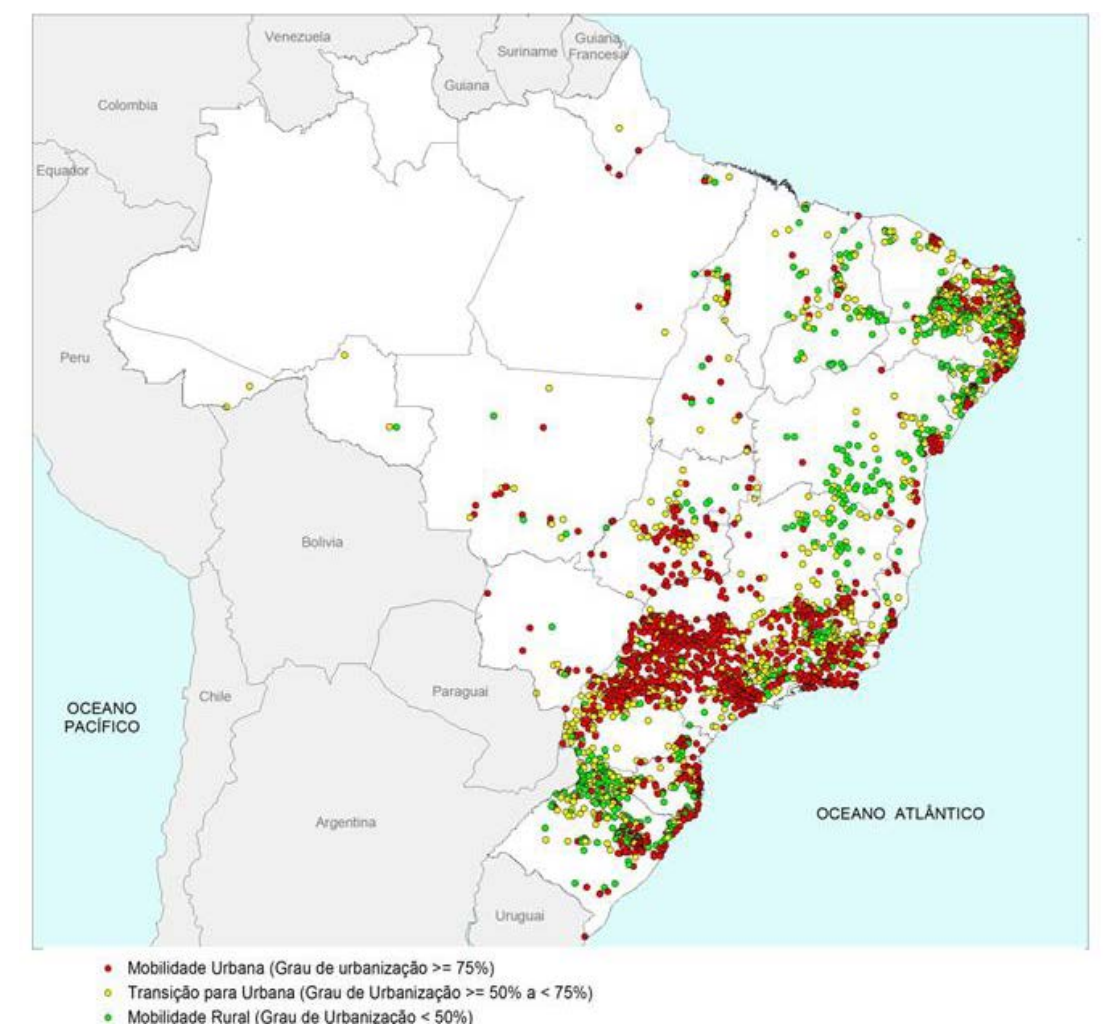

(fluxo superior a 10\% do total de pessoas do município que estuda ou trabalha)

Fonte: Galindo et al. (2015).

Para uma análise mais específica, Galindo et al. (2015) estratificaram os dados de fluxo pendular por grau de urbanização. Percebe-se que à exceção do Sudeste, do litoral e da região de Goiânia-Brasília, boa parte dos fluxos pendulares acima do clássico recorte dos $10 \%$ está relacionada a áreas com grau de urbanização não muito alto (entre $50 \%$ e $75 \%$ ) ou mesmo baixo (inferior a 50\%). Supondo um rebatimento considerável entre a situação do domicílio com a atividade predominante da PEA, muitos destes fenômenos estariam invisíveis aos recortes tradicionais (Galindo et al., 2015).

Estes resultados por um lado, confirmam a intensidade da mobilidade pendular no entorno de grandes e médios centros, fundamentalmente entre municípios componentes de ACPs (Áreas de Concentração de População). Por outro lado, mostram uma intensa mobilidade em municípios com menor grau de urbanização, abaixo dos cortes estabelecidos em outros estudos. Essa mobilidade "rural" merece ser compreendida, pois demarca um fenômeno pouco contemplado pela literatura e disseminado por várias porções do território, e subjacente a esse fenômeno podem se encontrar novas relações e novas formas de trabalho em atividades do setor primário, particularmente ligadas à agroindústria e ao agronegócio, ou as velhas formas de expan- são das periferias urbanas sem a devida compatibilização legal das leis de perímetro urbano municipal (Galindo et al., 2015).

A aproximação da relação rural-urbano pode ser percebida com os dados do IBGE sobre atividades e situação do domicílio (rural ou urbano). Dos dados se observa que o percentual de ocupados em atividades não agropecuárias aumentou de 11,54\% em 1996, para 14,71\% em 2006. No Sul está o mais alto percentual: 20,74\%. Ainda considerando-se as pessoas que vivem em área rural e não trabalham em atividade agropecuária, seu percentual é bem mais alto em regiões metropolitanas: 30,56\%. Trata-se de uma demonstração da atratividade do trabalho e do meio urbano em detrimento do rural, notadamente em espaços consolidados.

Essas constatações demonstram o risco de premissas eminentemente urbanas que impedem a observação do fenômeno de atração em si (o fluxo), que contrariam inferências já consolidadas entre os estudiosos sobre a correlação e causalidade do fluxo com a "intensidade urbana". Esse achado reforça a necessidade de observar o fenômeno sem premissas e preconceitos, de modo a reconstruir a interpretação e a representação das dinâmicas territoriais (Galindo et al., 2015). 
Frente a essas limitações, a experiência francesa de construção das bacias de vida e das regiões de emprego (trabalho) não descarta o que na Europa se considera como municípios rurais. A escala pode ser outra, mas se percebe uma coesão e integração entre áreas com menores características urbanas, em que pese o fato de o governo francês adotar proxies para representar o fluxo, ainda mais depois de não possuir mais informações de fluxos de acessos a serviços (Galindo et al., 2015).

Esse fluxo restrito a trabalho e estudo, embora receba crítica de Jardim (2011), é sabidamente o fluxo de maior volume em qualquer aglomeração, ademais é disponível via Censo Demográfico. Como ponto negativo, o uso limitado desse fluxo possui duas fragilidades. Uma delas é a resultante da aplicação dos pesos da amostra. Simplifica-se para se considerar que uma pessoa com as mesmas características socioeconômicas mapeadas na amostra do Censo possui a mesma situação do ponto de vista do fluxo pendular (Galindo et al., 2015). O outro ponto negativo trata da comparação histórica, pois de acordo com apontado por Moura et al. (2013), há diferenças entre as variáveis disponíveis nos censos de 1970, 1980, 1991, 2000 e 2010 quanto ao fluxo pendular. Os Censos de 2000 e 2010 são mais compatíveis, mas ainda assim, a formulação da pergunta é distinta: no de 2000 foi levantada em apenas uma questão, independentemente do motivo do fluxo, se trabalho ou estudo; no de 2010, foram feitas perguntas específicas para cada um destes fluxos, e ainda se indagou, no caso do deslocamento para trabalho, se o retorno deste movimento é diário, e o tempo habitual para realizá-lo (Galindo et al., 2015). A despeito dessas diferenças, considerase que o benefício custo da opção sustenta a escolha de não trabalhar com premissas e proxies a priori.

No próprio estudo da REGIC de 2007 do IBGE, consta como um dos critérios de delimitação do entorno das ACPS, a proporção de no mínimo $10 \%$ da população com 15 anos ou mais que trabalha ou estuda deslocando-se para outro município. Destaca-se o fato de se proceder com exclusões de municípios do entorno por não apresentaram continuidade na mancha urbana e os localizados distantes dos limites da área urbana, uma vez que os fluxos de movimento pendular pesquisados não separam os fluxos diários de outros fluxos, que seriam os relevantes para estes casos (IBGE, 2008b). Deste modo, fica claro em IBGE (2008b) que o uso de movimentos pendulares diários são essenciais para um ajuste mais apurado das relações. Estes dados, contudo, não existiam ainda em 2008, pois o Censo de 2000 não discernia o que era diário e o que não era, além de manter mesclados os motivos de estudo com os motivos de trabalho.

Percebe-se que, embora os critérios de identificação e classificação dos diversos estudos apresentados tenham diferenças de corte dos patamares mínimos, registra-se que nessa trajetória há um conjunto de informações que estão sistematicamente presentes como definidoras de aglomerações urbanas de natureza metropolitana ou não metropolitana, ou seja, há uma base de indicadores bastante comum. Foram considerados: tamanho da população, crescimento, densidade, ocupação predominante, grau de urbanização e proporção de ocupados em atividades urbanas; num dos casos, as ligações telefônicas com o município central. Indicadores de ordem econômica e social agregaram-se a estes, servindo de parâmetro para a classificação das cidades centrais na rede urbana brasileira.

Quanto à relação entre municípios, os deslocamentos pendulares da população e a continuidade da mancha de ocupação foram as principais informações (Galindo et al. 2015). Esta constatação é reforçada no recente estudo de Arranjos Populacionais (IBGE, 2015), ou seja, mesmo com toda a evolução das análises e das ferramentas desde o seminal estudo presentem em IBGE (1972), a importância do fluxo pendular só tem se reforçado. O que se aprimorou, principalmente no Censo Demográfico foi 0 detalhamento e identificação de fluxos diários e a separação dos motivos de estudo e de trabaIho. Neste contexto, a seção seguinte discorre sobre o método e cálculo adotados por este estudo para se determinar os fluxos e seus pontos de corte.

\section{Método e cálculo}

\subsection{Referências de apoio}

Para a definição de um método de delimitação de unidades espaciais mínimas para uso na representação de rede urbana, alguns conceitos consagrados permanecem válidos. A delimitação por meio de critérios de atratividade e dependência mantém o princípio da Teoria do Lugar Central de Christäller (1966: 1933). O autor não defendia a primazia de um lugar com base na concentração populacional, mas há uma forte correlação. O foco de sua explicação sobre a centralidade está relacionado à disponibilidade e especialização dos serviços, justificados a depender de uma demanda que torne 
viáveis serviços mais especializados em um determinado local. O transporte, as possibilidades de acesso e a distância (em verdade unida à velocidade e compreendida de melhor forma como tempo de deslocamento) limitam essa influência Neste sentido trabalhar com deslocamentos por emprego faz bastante sentido, ainda mais se observada a maior intensidade de mão de obra no serviço e comércio do que na indústria.

A indústria teve maior atenção com a contribuição de Boudeville (1972) na discussão de polos de crescimento, mas não deixou de seguir os princípios já apresentados por Christäller (1966: 1933). Sobre os tipos de região, Boudeville (1972) apresenta três classificações: homogênea, polarizada e regiões-plano. Para os objetivos colocados neste estudo, a regionalização com base na homogeneidade não é muito útil, se adequando melhor a objetivos de programas federais de áreas deprimidas e vulneráveis como os Territórios da Cidadania, por exemplo. As duas últimas seguem a lógica da Teoria do Lugar Central, aumentando de complexidade no segundo tipo proposto por Boudeville (1972). Observa-se que para a rede urbana a Teoria do Lugar Central ainda é mais aderente. As teorias de Boudeville são mais úteis para a economia regional e o desenvolvimento industrial. As atividades secundárias (indústria) cada vez mais perdem participação nos grandes centros urbanos, se deslocando mais para as bordas das delimitações de aglomerações urbanas, ainda que todos os serviços atrelado às indústrias mantenha seus fortes impactos na centralidade destes aglomerados.

O estabelecimento de uma hierarquia de centros está presente em ambas as vertentes, mas como se discute neste texto a fase inicial de delimitação de áreas integradas, deixa-se essa discussão para a próxima etapa. De todo o modo, ambos os autores possuem concepções convencionais, simplificadas e idealizadas, como toda boa teoria, tem algo a contribuir desde que não se assuma cegamente seus preceitos.

O modelo gravitacional de Isard (1960) pode ser considerado também uma grande simplificação do tema da atração. Basicamente se relaciona alguma variável em geral econômica de algum local (município, região, aglomeração etc.) com a distância a outros locais, na expectativa de indicar a força de atração de um núcleo urbano. Neste sentido e também de forma simplória Tobler (1970) é citado pela célebre "primeira lei da geografia": "everything is related to everything else, but near things are more related than distant thing" (Tobler, 1970, p. 236). Tanto Isard (1960) quanto Tobler (1970) propõem formas de cálculo para suas proposições, mas não avançam muito na simplicidades e idealização de Christäler, no que diz respeito aos objetivos deste texto.

Além da contribuição da teoria, o uso institucional de formas de divisão espacial adotadas por órgãos e governos (ver seção anterior) dão pistas sobre como trabalhar com os dados de fluxo pendular, ainda que nenhum deles tenha usado o dado mais preciso (fluxo pendular apenas diário). Além deles, outro conceito institucional útil é a antiga definição francesa de bacia de vida ${ }^{2}$, antes da alteração ocorrida em 2012, que retirou a relação de emprego do conceito. $A$ bacia de vida em síntese pretende definir os limites de um espaço de convívio cotidiano comum. Outro apoio é o também francês conceito de zonas (ou regiões) de trabalho (ou emprego) ${ }^{3}$, um espaço geográfico dentro do qual a maior parte da PEA vive e trabalha e as empresas podem encontrar a mão de obra essencial para ocupar os empregos oferecidos.

Nas etapas posteriores para estruturar a rede e hierarquizar os territórios, outros conceitos serão agregados, com vínculos maiores a representação da rede urbana propriamente dita (seus links). De início podem ser citadas as tipologias indicadas por Burgess (1927), modelo das zonas concêntricas de Hoyt (1939), modelos dos núcleos múltiplos de Harris e Ullman (1945), bem como os entendimentos de transporte trazidos pela compreensão da evolução de uma rede de transporte por Taaffe, Morril e

\footnotetext{
$2 \quad$ Disponível em: <http://www.insee.fr/fr/methodes/default.asp?page=definitions/ bassin-de-vie.htm>. Acesso em: 20 outubro 2016.

3 Disponível em:

$<$ http://www.insee.fr/fr/methodes/default.asp?page=definitions/ zone-emploi.htm>. Acesso em: 20 outubro 2016.
} 
Gould (1963), da hierarquia de Ligações por Pred e Tornquist (1973) e de ligações do sistema de transporte por Manhein (1979).

Para este texto, o uso do geoprocessamento ainda que exaustivo, não teve complexidade. Nas próximas fases, em continuação ao que foi proposto aqui, além dessa base teórica essencial, outros conceitos, métodos e ferramentas poderão auxiliar na construção da rede urbana. As noções de dependência espacial (local e global) e autocorrelação espacial na construção de indicadores (a exemplo da estatística LISA Local Indicators of Spatial Association - Anselin, 1995) utilizados na estatística espacial e nos programas de geoprocessamento hoje disponíveis, além do método estrutural-diferencial são possíveis ferramentas de apoio à análise espacial das relações entre municípios, aglomerados e regiões. Nesse sentido, Monastério (2011) faz uma revisão que serve de ponto de partida para conhecer indicadores que podem servir na identificação da desigualdade regional, a exemplo dos índices de Williamson (1965) e de Theil (1989), da especialização regional (ex.: quociente locacional, coeficiente de especialização e índice de dessemelhança de Krugman, 1993), da localização setorial (ex.: Índice de Hirschman-Herfindahl, CL, Gini para localização) e do potencial de mercado, entre outras contribuições.

Por fim, há uma preocupação que deve estar sempre presente na escolha do recorte espacial a se adotar: o MAUP, sigla em inglês para o problema de unidade de área modificável de Oppenshaw e Taylor (1981). Em síntese indica que a definição da escala e da agregação a ser usada interfere no resultado. Oppenshaw (1983) apresenta uma forma de tentar enfrentar este problema do zoneamento automático com o uso do AZP (sigla em inglês para processo de zoneamento automático), que se inicia com a definição do número de agregações que se deseja, mas não é aplicável diretamente na proposta que se coloca neste texto.

\subsection{Escolha da fonte dos dados}

Ao se optar por trabalhar com um determinado dado ou informação é necessário identificar quais bases de dados estão disponíveis e qual ou quais são apresentadas de maneira satisfatória para o cumprimento dos objetivos da analise. Dados de emprego podem ser obtidos por algumas bases de dados (RAIS, CAGED, PNAD, CENSO). A opção pelos dados do Censo se justifica por alguns motivos.

Se é verdade que a RAIS é um dado Censitário, diferente da Amostra do Censo, os dados da RAIS não incluem trabalho informal e nem possuem informação passível de identificar local de moradia e local de trabalho, ainda que possua um campo que em teoria poderia servir para isso. OCAGED se refere a fluxo de empregos (admissões e demissões) e não o estoque, já a PNAD, apesar de ter uma maior periodicidade, não permite representatividade para município.

Há uma fonte importante de dados sobre ocupações na agropecuária que são os registros da agricultura familiar, denominado de DAP - Declaração de Aptidão ao Pronaf (Programa Nacional de Fortalecimento da Agricultura Familiar), mas o conceito de agricultura familiar pressupõe de forma geral que o estabelecimento de moradia é o mesmo de trabalho (ou próximo tendendo a ser no mesmo município) e para o estudo em questão não interessam fluxos intramunicipais. Deste modo, identificou-se os dados da Amostra do Censo Demográfico 2010 como os únicos que permitem a análise proposta neste texto.

\subsection{Tratamento dos dados}

Os dados foram baixados da base compactada de microdados da amostra disponibilizados pelo IBGE via FTP para cada estado, incluindo os dois arquivos do estado de São Paulo. Os arquivos individualizados em formato de texto foram descompactados e seguindo o dicionário foram convertidos em arquivos de SAS, gerando um arquivo final de mais de $40 \mathrm{~Gb}$. Deste arquivo foram selecionadas as variáveis de interesse que deram origem ao arquivo bruto (de mais de $15 \mathrm{~Gb}$ em SAS) para se calcular e agregar os campos do arquivo final (município de moradia, município de trabalho, total de trabalhadores que se deslocam de um para outro, total de trabalhadores da origem, total de traba- 
Ihadores no destino e marcador de deslocamento diário). Após agregar os microdados, gerouse um arquivo com 148.554 observações incluindo dados dos que não trabalham, trabalham em mais de um emprego (neste caso não se indica onde nem se o movimento é diário), trabalham no mesmo município que moram e não tinham informado o município ou país de destino. Destes, após a limpeza restaram 131.590 pares municípioxmunicípio ou municípioxpaís e depois de retirados os pares com países ficaram 130.246 pares. Retirando os que trabalham no mesmo município, soraram 124.681 como pares de fato. Finalmente destes foram separados apenas aqueles com fluxos diários totalizando 55.247 pares. A tabela foi complementada com a identificação dos pares que são contíguos por meio de processamento espacial com uso de software desenvolvido pelo Ipea (IpeaGeo).

A retirada do estudo se deve ao fato de não ser possível isolar deslocamentos não diários, como é possível para o deslocamento para trabalho. Isso melhora a qualidade do dado, ainda que não evite que fluxos não pendulares se incluam. Foram observados fluxos diários a grandes distâncias. Inicialmente suspeitou-se de atividades com alta remuneração, mas ao observar os microdados verificou-se que em geral trata-se de ocupação com baixas remunerações muitas vezes vinculadas a atividades na construção civil e na agricultura. Há casos relacionados a ocupações temporárias que podem ser a principal atividade, com isso um deslocamento diário casa trabalho foi estabelecido durante o tempo em que o trabalhador temporário de fato morava no município ou próximo dele durante um período do ano, mas quando se cruza o dado de município de trabalho principal, município de residência no momento da entrevista e a confirmação de que se ia todo dia do trabalha para casa (neste caso a casa temporária) gera-se a confusão. Isso demonstra uma fragilidade neste dado do IBGE para identificar fluxos pendulares propriamente ditos. Para minimizar, mas não eliminar este efeito retiramos fluxos de trabalhos não diários, os fluxos de estudo (já que não há informação sobre fluxo diário) e os fluxos diários a trabalho a grandes distâncias. Estes últimos pelo critério de contiguidade já são eliminados automaticamente. O fluxo não pendular é importante, mas pode distorcer relações que definem áreas de convivência, ou bacias de emprego ou de vida. Sua utilidade está mais relacionada na identificação dos links da rede urbana do que na sua apropriação para definir uma área contígua, integrada e coesa.

A linha de corte, ou seja, o percentual para o qual se considera que o fluxo é suficiente para determinar a agregação é relativizado pela própria distribuição desses percentuais para um mesmo estado (ou estados quando se ultrapassar as fronteiras estaduais).

A contiguidade limita a inclusão de municípios na delimitação, conforme o que for observado na análise dos dados. Considera-se que o método é cauteloso e conservador ao utilizar apenas o fluxo diário e apenas as motivações de trabalho, já que de fato a intenção seria identificar uma agregação mínima de municípios que em tese deveria ser indissociável quando analisada frente às regionalizações existentes no país e nos estados.

\subsection{Definição dos critérios}

Definiu-se como já explicado utilizar o dado de emprego para analisar os fluxos pendulares, mas com os dados de emprego podem ser combinados outros dados gerando indicadores ou variáveis diversas. Como a distribuição de empregos no Brasil é muito desigual em função da desigualdade regional e populacional, optouse por tentar captar um amplo aspecto do trabaIho. Importa saber quais municípios são grandes atratores do ponto de vista do fluxo absoluto. Isso entretanto não basta pois há uma infinidade de pequenos municípios que podem ter estreita relação com seus vizinhos indicando uma integração e coesão maior por conta de sua dependência ou de sua atratividade. Decidiu-se então abordar também a importância relativa de um município com outro. Essa participação relativa pode se dar tanto no peso do trabalhadores que se evadem do município de origem, quanto no impacto da massa trabalhadora no município de destino, sendo necessário mensurar essas duas participações. Atendendo 
ao ponto de corte de algum desses critérios, o município é incluído na definição de novas delimitações espaciais agregadas.

Restava definir o critério de corte. A maior parte dos critérios de corte definidos em pesquisas que se propõem a agregar unidades espaciais usa algum parâmetro de definição de faixas ad hoc, ou busca justificar os motivos de sua escoIha. Qual seria a melhor solução? Adotar um parâmetro comumente usado (ainda que não tenha justificativa)? Utilizar um percentil qualquer? Adotar quebras claras? Quantil? Intervalo igual? Desvio padrão?

Há sempre essa dúvida e pelo que se depreende de Oppenshaw (1983) os resultados serão diferentes a depender da escolha. Com a pretensão de ser mais imparcial na definição do ponto de corte, optou-se por trabalhar com o critério de quebras naturais (natural jenks), em teoria retira-se da decisão do autor o poder de definir o corte conforme seu interesse (e tendendo a buscar um resultado que reforce sua tese) apoiando-se num critério estatístico baseado na menor variância possível dentro de uma faixa e maior possível entre as faixas.

Rodou-se esse procedimento dentro da própria classificação do QuabtumGis, após incorporar o complemento OurSins para gerar as linhas de fluxo. Inseridas as ais de 55 mil linhas de fluxo o QuantumGis calculou a pedido duas faixas. Com isso, supostamente estaria se criando um ponto de corte entre os "escolhidos" e o "renegados" do ponto de vista do fluxo. Porcedeu-se desta fora para as três variáveis e foram mantidas as linhas de fluxo que atenderam ao menos um dos critérios.

Percebeu-se um problema no QuantumGis no processamento da quebra natural, por partir de um algoritmo aleatório que seleciona uma amostra dentro do universo das mais de 55 mil linhas, ele apresenta resultados diferentes a cada rodagem. A intenção é no futuro sugerir aprimoramentos para isso, ou processar as quebras fora do ambiente GIS, mas por enquanto para testar o método, rodou-se 100 vezes cada critério (durante essa rodagem os resultados se repetiram algumas vezes) e selecionou- se o critério menos rígido. Caso fosse feita a escolha pelo mais rígido (pontos de corte mais altos) restariam poucos municípios na agregação.

Os parâmetros utilizados se apresentam na tabela 3 a seguir. Nela foram incluídos para comparação o ponto de corte caso se adotasse percentil 99 e caso se adotasse o parâmetro mais restritivo gerado pelo Quantum Gis nas 100 repetições.

Tabela 3: Parâmetros de corte.

\begin{tabular}{llll}
\hline & Parâmetros & Percentil 99 & $\begin{array}{l}\text { Opção mais } \\
\text { restritiva }\end{array}$ \\
\hline Destino & $2,97 \%$ & $6,45 \%$ & $7,81 \%$ \\
Origem & $7,09 \%$ & $11,37 \%$ & $13,98 \%$ \\
Absoluto & 13.567 & 1.586 & 40.394 \\
\hline
\end{tabular}

Nas próximas seções se demonstram os resultados, tecendo comentários na seção imediatamente seguinte para a justificativa de se adotar as RMs como teste.

\section{Por que usar as regiões metropoli- tanas para teste do método?}

As regiões metropolitanas são citadas nas Constituições do Brasil desde a CF de 1967, há quase 50 anos e estão presentes em estudo do IBGE sobre a "Divisão do Brasil em regiões funcionais urbanas", realizado em 1966 e publicado em 1972. As primeiras regiões metropolitanas instituídas, ainda sob a decisão da União, datam de 1973. Destes marcos para cá inúmeros estudos trataram de abordar o tema, discutindo, criticando e propondo novas configurações para os limites metropolitanos. As RMs passaram a ser, portanto, objeto exaustivo da temática urbana, tendo sido apropriadas e interpretadas por pesquisadores e especialistas, e conhecidas pelo público em geral. Submeter um método de delimitação espacial a testes sobre essas aglomerações permite expandir o rol de críticos ao método, possibilitando que mais profissionais contribuam para seu ajuste. Ao abordar apenas as RMs cujos núcleos são capitais estaduais, amplia-se ainda mais este rol. Ainda foram incluídas nos testes as capitais que não constituem RMs, apenas para verificar conforme o método se assim devem permanecer. 
A crítica construtiva à delimitação das RMs não é, portanto, privilégio desta proposta. Críticas deste tipo já foram feitas pelo próprio Ipea nos anos 1990, enquanto coordenador do estudo "Caracterização e Tendências da Rede Urbana do Brasil" (IPEA, 2002a e b), elaborado em conjunto com a Universidade Estadual de Campinas (UNICAMP), o Núcleo de Economia Social, Urbana e Regional (NESUR) e o IBGE. Os resultados do estudo apontam para a incompatibilidade entre as aglomerações institucionalizadas (18 RMs) e a espacialidade composta a partir da aplicação dos critérios, apontando municípios inseridos por lei que não correspondiam aos limites mínimos dos indicadores e municípios que atendiam aos critérios e que não foram inseridos nas respectivas unidades, além de aglomerações não institucionalizadas que apresentavam características de metrópoles.

O Observatório das Metrópoles (Ribeiro, 2009) também indicou a dissociação entre os limites das unidades institucionalizadas e a extensão da aglomeração urbana: 39,8\% dos municípios apresentaram níveis baixo ou muito baixo de integração à dinâmica da aglomeração, podendo ser considerados como não integrados ou em integração inicial. Das 37 unidades analisadas, 15 foram consideradas metropolitanas.

Com os resultados do Censo Demográfico 2010, o Observatório das Metrópoles reelaborou a tipologia dos Níveis de Integração, ampliando o número de municípios considerados em razão do aumento do número de unidades institucionalizadas e apontou um outro lado do problema: as mudanças na morfologia sob os auspícios do automóvel, das tecnologias de informação, do afastamento da localização de firmas e habitação vêm provocando uma "metropolização expandida" (De Mattos, 2004, 2010) ou periurbanização. Das 51 Regiões Metropolitanas (RMs) existentes em agosto de 2012, 11 tinham caráter de RM. Do total de 945 municípios nelas inseridos, $28 \%$ tinham caráter metropolitano.

Também com base nos dados do Censo Demográfico de 2010 e nos critérios empregados por Galvão et al., (1969) para a identificação das nove primeiras regiões metropolitanas institucionalizadas no Brasil nos anos 1973 e 1974,
Castello Branco, Pereira e Nadalin (2013) identificaram quais seriam as RMs em 2010. Os limites mínimos estabelecidos nos anos 1970 quanto a tamanho populacional, densidade demográfica, fluxos casa-trabalho e principalmente percentual da população economicamente ativa (PEA) ocupada em atividades industriais mostraram-se pouco restritivos como referência de comparação com as atuais RMs, cuja delimitação de municípios inseridos foi definida pelos estados. Outros critérios, como crescimento elevado da população, ocupação em atividade industrial, valor da produção industrial e ligações telefônicas foram modificados ou descartados.

As RMs estimadas por Castello Branco, Pereira e Nadalin (2013) foram classificadas com base no grau de metropolização, caracterizado pela alta especialização do uso do solo urbano (Davidovich e Lima, 1975). No estrato metropolitano, o estudo destacou a Macrometrópole Paulista, formada pela junção de várias áreas metropolitanas contíguas com ligações muito fortes entre os municípios que as compõem. Além dessa, as áreas metropolitanas do Rio de Janeiro, Brasília, Belém, Fortaleza, Recife, Salvador, Belo Horizonte, Curitiba, Porto Alegre e Goiânia. Como "áreas metropolitanas incipientes" (Davidovich e Lima, 1975, p.61) foram apontadas São Luís, Teresina, Natal, João Pessoa, Maceió, Vitória, Ribeirão Preto, Londrina, Florianópolis, Joinville e Cuiabá. Na categoria "áreas metropolitanas não consolidadas e ainda em formação", introduzida em substituição à noção de "áreas submetropolitanas" (Davidovich e Lima, 1975, p.61) encontram-se Porto Velho, Aracaju, Juiz de Fora, São José do Rio Preto e Caxias do Sul.

Além de oferecer a relação de RMs oriundas dos critérios reaplicados, os resultados da simulação foram comparados às RMs reconhecidas oficialmente na data do Censo Demográfico 2010. Mostraram que, segundo os autores, o "Brasil metropolitano" relativo ao conjunto de unidades institucionalizadas é de composto por um menor número de unidades efetivamente em condições de serem consideradas metropolitanas (26 versus 39); essas, por sua vez, en- 
globam aproximadamente metade do número de municípios que o conjunto oficial (328 versus 671); com maior nível de integração por deslocamentos casa-trabalho; uma área territorial cerca de três vezes mais compacta e mais densa; e ainda com mínimas diferenças em termos de porte populacional e econômico. É importante ressaltar uma recomendação dos autores no sentido de que "a utilização de uma única metodologia para delimitação de RMs no país se mostra extremamente útil no sentido de garantir a comparabilidade das estatísticas oficiais dessas áreas." (Castello Branco, Pereira e Nadalin, 2013, p.30)

Em texto pós-Estatuto da Metrópole, Moura e Hoshino (2015, p. 3) reforçam o coro:

\begin{abstract}
Desde a Constituição Federal de 1988, que franqueou aos estados a competência para a instituição de RMs, AUs e microrregiões (MRs), o número de RMs no país se elevou das 9 unidades instituídas por Lei Federal (14/1973 e 20/1974) para mais de 60, distribuídas entre os estados da federação, a grande maioria, seguramente, sem os predicados mínimos que lhes atribuam verdadeira natureza metropolitana. Essa proliferação casuística e o descaso reiterado, por parte dos estados, para com critérios que distingam aglomerações polarizadas por metrópoles daquelas que correspondem a simples aglomerações urbanas implicaram em grandes obstáculos à promoção de ações nesse setor, sobretudo por parte do governo federal.
\end{abstract}

Moura e Hoshino (2015, p. 4-5), contudo, vislumbram dias melhores na vigência do Estatuto:

\begin{abstract}
De se salientar que, para angariar status de metrópole, o núcleo da unidade deve ter, no mínimo, a área de influência de uma capital regional, conforme classificação do IBGE. Essa exigência poderia ser mais restritiva, porém está adequada à grande diversidade da rede urbana brasileira na qual, em determinadas regiões de menor densidade de ocupação, centros regionais detêm efetivamente a condição de metrópoles. Com base nessa definição, uma "região metropolitana" só poderá ser instituída em relação a uma aglomeração urbana que configure uma metrópole. Mais do que isso, a RM instituída mediante lei complementar estadual que não atenda a este requisito será enquadrada como aglomeração urbana para efeito das políticas públicas a cargo da União (art. 15).
\end{abstract}

Do conjunto de estudos apresentados, depreende-se que é antiga e continuada a busca por conceituar, identificar e delimitar aglomerações urbanas, caracterizando-as conforme sua natureza. Anote-se que, nessa busca, a intenção governamental de instituir regiões-programa foi e segue sendo fortemente motivadora de novas pesquisas, que atualizam pressupostos e conceitos, conforme os avanços da literatura internacional sobre o processo de metropolização. Mesmo assim, se por um lado essas pesquisas se tornam precisas quanto ao conceito adotado e ao dimensionamento da extensão dessas aglomerações, apresentando o fato metropolitano em sua essência, por outro, a contínua institucionalização de unidades regionais não incorpora esses resultados na delimitação do território formal. Esse fato segue levando a incompatibilidades, seja por exceder o tamanho dessas unidades em relação aos aglomerados, seja por segmentar esses aglomerados, fragmentando espaços efetivamente integrados em uma única dinâmica (Galindo et al., 2015).

Usar as RMs como teste permite, portanto, cumprir dois objetivos relacionados: verificar a validade do método e analisar a adequação da configuração formal das RMs. Na seção seguinte de forma resumida, serão analisados os comportamentos das 2 capitais estaduais sob estes pontos de vista.

\section{Aplicações teste sobre as Capitais e suas RMs}

Antes de apresentar os resultados e sua análise para as RMs tomadas como exemplo, cabem algumas observações quanto à representação gráfica e às suas causas. Como o intuito é verificar a aderência dos municípios a uma RM analisando sua dependência e atração com base nos critérios estabelecidos neste trabalho, decidiu-se deixar clara a configuração original das RMS (quando instituídas pela União, previamente à Constituição de 1988). Deste modo destaca-se enquanto limites de polígonos a capital, a RM original e a RM atual (2010). Estas são as referências, tanto para crítica quanto para teste do método.

O resultado do método, por sua vez, é constituído pelos fluxos, representados por linhas definidas por faixas de espessura correspondentes 
ao seu valor absoluto. Cabe ressaltar que o critério de corte para definir um fluxo relevante (e assim plotado no mapa) envolve também o valor relativo na origem e no destino. Deste modo, é possível que existam fluxos até mais expressivos do que os apresentados no mapa, em termos de valor absoluto, mas que não tenham tanta relevância relativa quanto os explicitados no mapa.

Para contribuir com a leitura, acrescentou-se ainda o total de empregos - sempre com base nos dados da amostra do censo expandida pelo peso amostral - por meio de diagramas circulares proporcionais em diâmetro ao estoque de emprego. Por fim, deixamos clara a escala do mapa para que se tenha uma compreensão das distâncias entre os municípios, mesmo que de forma simplificada tenha sido adotado o centroi- de dos polígonos dos municípios como os nós (centro da circunferência de estoques e pontos de ligação entre os fluxos). Ainda que não se esteja aqui defendendo ou adotando o modelo gravitacional de Isard (1960), acredita-se que isso auxilie na compreensão das relações.

Para a correta interpretação do mapa, ressaltase que os municípios destacados com o nome e o quantitativo de seu estoque de emprego, são apenas aqueles que se destacaram dentro dos critérios adotados como origem, ou destino, de fluxos significativos (do ponto de vista absoluto ou relativo), façam ou não parte de uma RM instituída. Por este motivo, em alguns mapas optou-se por ampliar a área visualizada (e, consequentemente, reduzir a escala) para que se observe o comportamento dos municípios às margens das RMs.

\subsection{São Paulo}

Figura 2: Delimitação espacial de São Paulo: Rede Urbana versus RM.

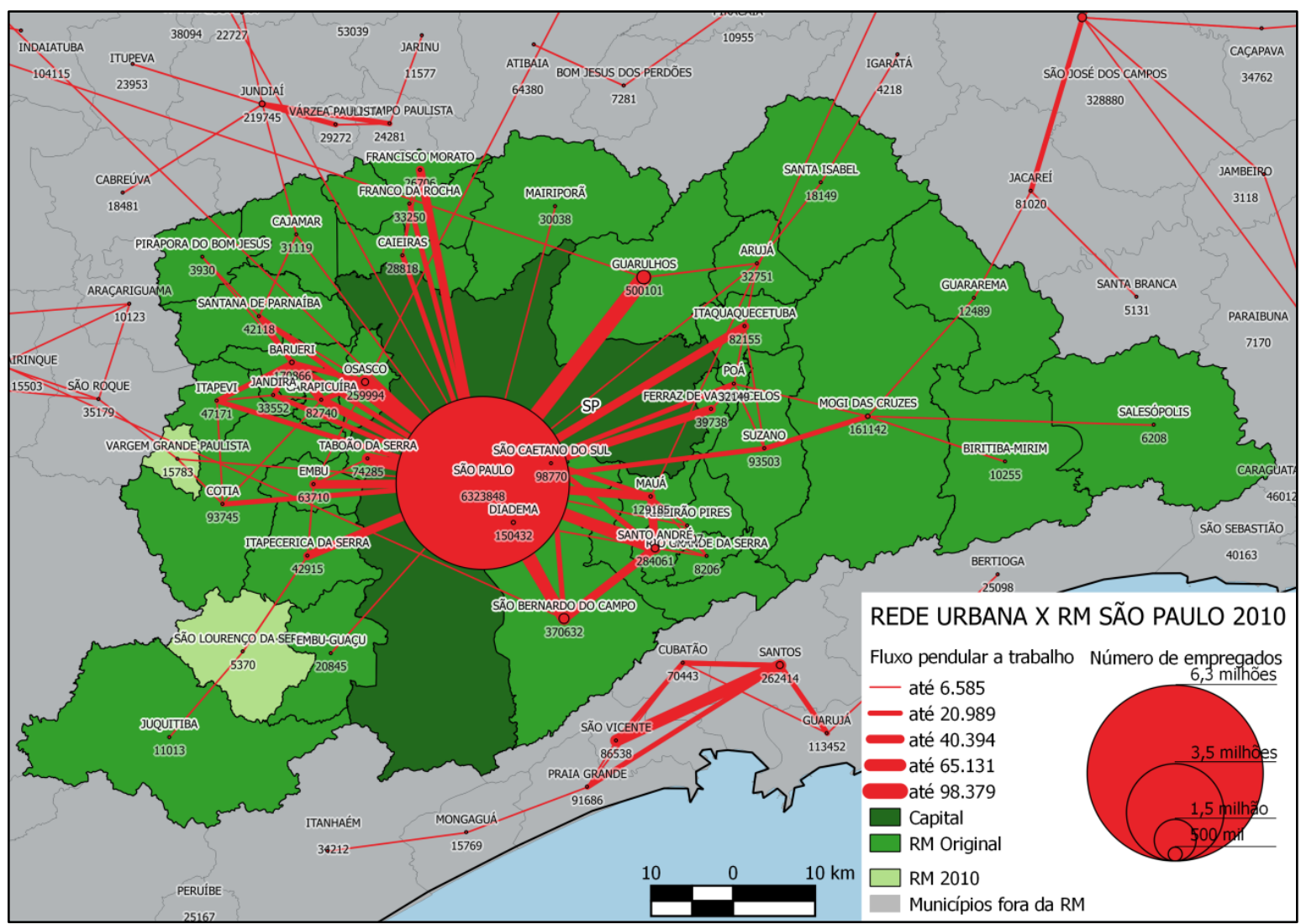


Todos os 38 municípios da RM atual possuem vínculo com a capital paulista, de acordo com os resultados do método, sendo 31 de forma direta (figura 2). A aderência dos municípios formalmente vinculados à RM é altamente satisfatória, sendo sintomático que da Região Metropolitana Original para a configuração de 2010 foram acrescentados apenas dois municípios (um deles por ter sido desmembrado posteriormente à Constituição de 1988). Só um município com relação direta com São Paulo foi excluído, por descontiguidade e distância, o que sugere limitações dos dados do IBGE na caracterização do fluxo pendular. Outros indiretos (vinculados a outros municípios da RM) também possuem essas características.

Uma região tão pujante deveria ter sofrido alterações do ponto de vista da integração e coesão de outros municípios, mas esta constatação em geral é remetida ao policentrismo que caracteriza o que passou a ser denominada de Macrometrópole de São Paulo, que estende seus limites a outras RMs paulistas. Sobre esta delimitação ampliada, percebe-se que o método identificou quatro "portas" (municípios) de entrada. A primeira delas é bastante simples referindo-se à possível inclusão imediata de Igaratá na RM de São Paulo pelo peso relativo dos trabalhadores de Santa Isabel naquele município.

Outra porta é Vargem Grande Paulista, município incluído na RM de São Paulo após 1988, que não por acaso tem vínculo mais forte com seu município de origem (Cotia). Seu elo significativo mais fraco é com São Roque (fora da $\mathrm{RM})$, um município que é atrator e repulsor a depender do município com que se relaciona. Incluir São Roque significaria incluir Mairinque, Araçariguama e Alumínio e, ao fim e ao cabo, agregar à RM de São Paulo, todos os municípios relacionados à Sorocaba (Votorantim, Salto de Pirapora, Araçoiaba da Serra, Iperó e consequentemente também Boituva).

Pela "porta" de Cajamar, a expansão da RM de São Paulo teria que agregar Jundiaí e toda a sua força atratora (Várzea Paulista, Campo Limpo Paulista - e consequentemente Jarinu -, Cabreúva, Itupeva e Louveira). De Louveira segue-se vinculando Vinhedo e Valinhos até alcançar Campinas fechando a "Macrometrópole" com toda a influência do entorno campinense (Hortolândia, Sumaré - e, consequentemente, Nova Odessa, Americana e Santa Bárbara d'Oeste -, Monte Mor e os vínculos ao norte de Campinas: Paulínia, Jaguariúna, Cosmópolis, Holambra, Santo Antônio de Posse, Artur Nogueira até Engenheiro Coelho).

Guararema é mais uma das "portas", a partir do município os laços se estendem para além da RM oficial de São Paulo, desde Jacareí até Cachoeira Paulista, incluindo os entornos de São José dos Campos e Taubaté numa sequência de vínculos par a par (ou no máximo entre três municípios) ao longo da BR-116 (via Dutra) e SP-770 (Ayrton Senna/Carvalho Pinto), incorporando os municípios de Santa Branca, Jambeiro, Paraibuna, Monteiro Lobato, Caçapava, Redenção da Serra, Tremembé, Pindamonhangaba, Roseira, Aparecida, Potim, Guaratinguetá, Lorena, Piquete e Canas.

Constata-se, como resultado do método, que os municípios da RM santista não se vinculariam à RM de São Paulo, como a figura 3 demonstra. Então, seria incluída numa expansão a influência de Campinas ao norte, passando por Jundiaí, Sorocaba a leste e São José dos Campos a oeste. Formam um tripé cujas pontas se encerram, respectivamente, em Boituva (O), Engenheiro Coelho (N) e Cachoeira Paulista (L). Seu início seria na RM atual, estando mais ao sul os próprios limites da capital Paulista ou para ser mais preciso a Sudoeste, Juquitiba. De maneira geral, essa delimitação segue, conforme demonstra a figura 3 , os eixos das rodovias federais BR-050 (via Anhanguera) (N), BR-116 (L e SO) e SP-280/BR-374 (Castello Branco) e BR272 (Raposo Tavares) (O) e suas respectivas alternativas rodoviárias estaduais. Nesta configuração ampliada a delimitação possuiria 92 municípios (população 2010 de 25,6 milhões, 13,4\% do Brasil e PIB 2012 a preços correntes de $\mathrm{R} \$ 1,0$ trilhão, 23\% do Brasil) 
Figura 3: Rede Urbana: Delimitação espacial expandida de São Paulo.

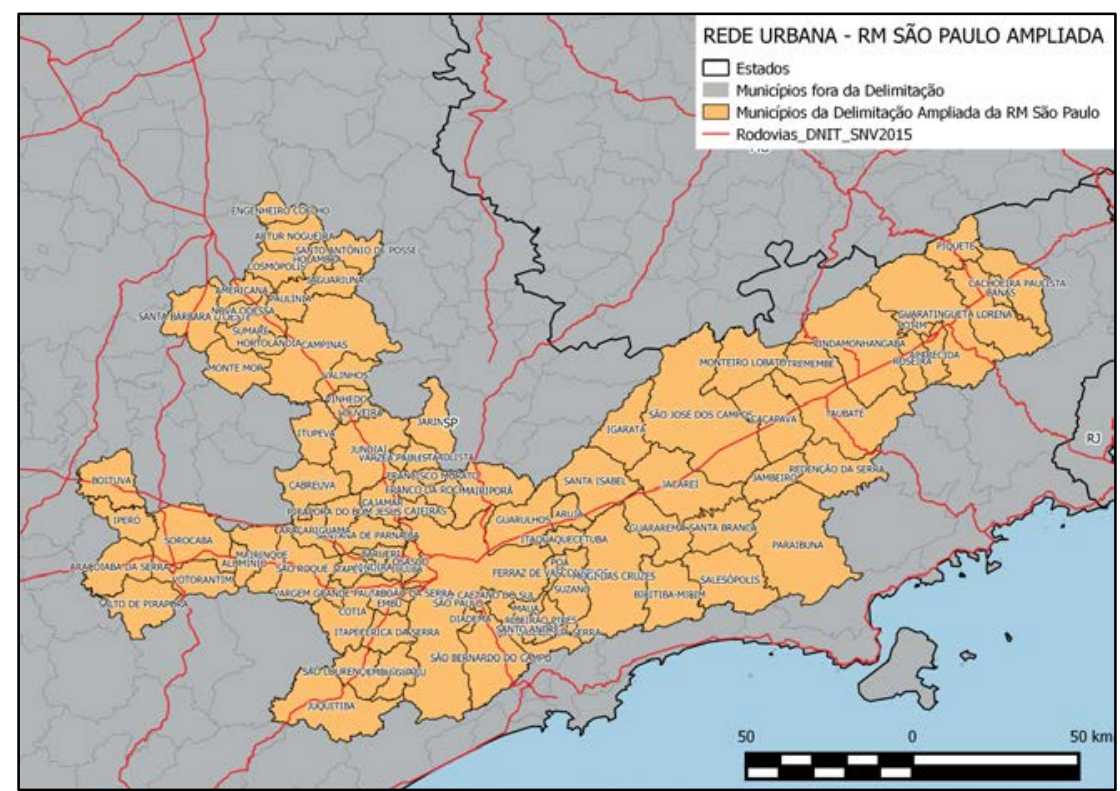

\subsection{Rio de Janeiro}

Figura 4: Delimitação espacial do Rio de Janeiro: Rede Urbana versus RM.

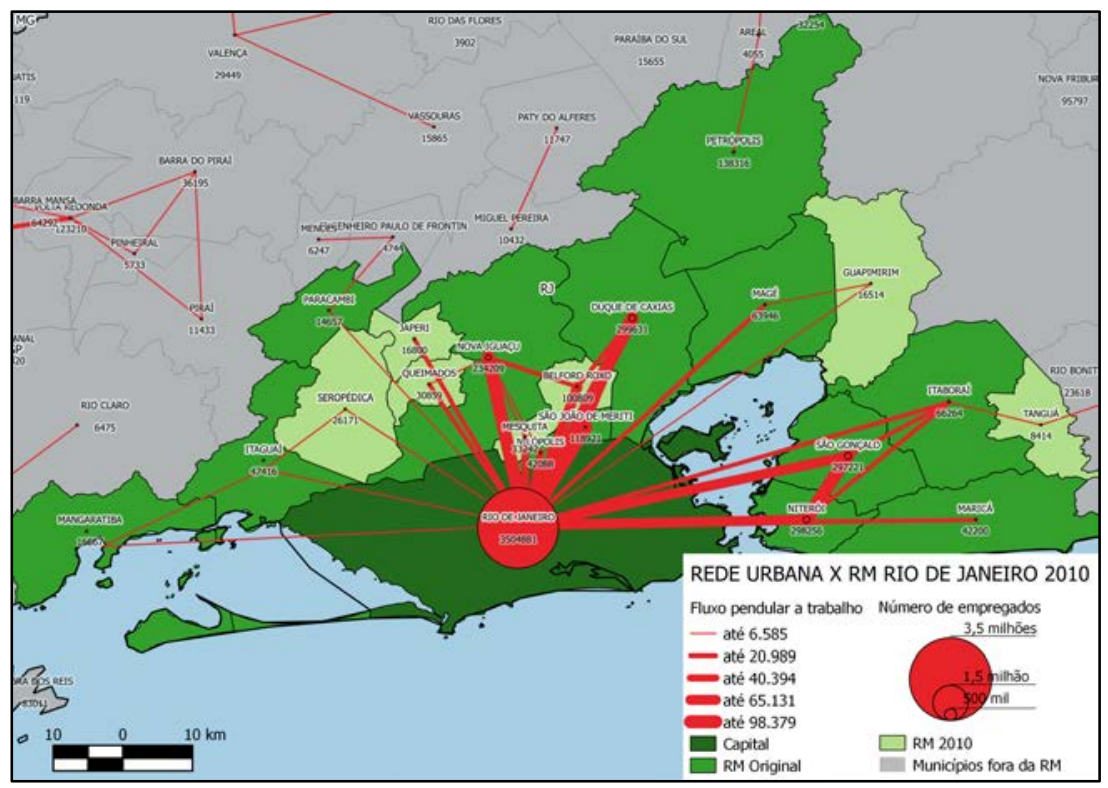

A Região Metropolitana do Rio de Janeiro tem sofrido constantes alterações nos últimos anos, em parte pelos desmembramentos que deram origem a instalação de 1993 a 2001 de Seropédica , Japeri, Queimados, Mesquita, Belford Roxo, Guapimirim e Tanguá. A inserção e exclusão de municípios ocorreram também para além dos desmembramentos, Petrópolis e São José do Vale do Rio Preto foram excluídos em 1993, Maricá em 2001 e Itaguaí e Mangaratiba em 2002. Itaguaí e Maricá retornaram em 2009.

A figura 4 apresenta a RM Original (ainda sem a exclusão de Petrópolis nem de Mangaratiba) e a de 2010, mas em 2014 foram incluídos Cachoeira de Macacu e Rio Bonito.

Comparando com o resultado da rede urbana, analisando exclusivamente o fluxo pendular diário a trabalho, Petrópolis de fato não parece ter relação significativa com o Rio de Janeiro 
(figura 4). Quase três mil pessoas vão de Petrópolis ao Rio de Janeiro trabalhar diariamente, mas em termos absolutos e relativos esse fluxo é fraco. Dos quase cinco mil que trabalham e são de Areal, 17,5\% trabalham em Petrópolis. Deste ponto de vista, nos termos propostos pelo método, relativamente Petrópolis é mais um núcleo de que depende Areal do que um dependente do Rio de Janeiro. O método mantém a indicação de exclusão de Petrópolis e sequer apresenta qualquer fluxo relativo para São José do Vale do Rio Preto.

Mangaratiba, excluído em 2002 por sua relação com Itaguaí e com o próprio Rio de Janeiro poderia ser mantido, bem como Rio Bonito (ainda que anexado apenas em 2014) por seu vínculo com Tanguá. Por fim, de forma indireta (por meio de Paracambi), há um vínculo observado com Engenheiro Paulo de Frontin e com Mendes, mesmo que tenham estoques de trabalho bem diminutos em função de seu porte populacional.

Além do retorno de Mangaratiba, portanto, a única possível diferença que o método apresenta como resultado é a inclusão de Mendes e de Engenheiro Paulo de Frontin.

\section{Resultados}

Dos 55.247 pares pendulares, o ponto de corte identificou 1.794 (74\% dos fluxos par a par do Brasil) totalizando 1.732 município envolvidos. No geral demonstrou boa aderência às Regiões Metropolitanas originais (antes da Constituição de 1988) e já aponta indícios de imprecisões marginais em algumas regionalizações já existentes. Esses 2.232 municípios se apresentam na figura 5. A dimensão desproporcional dos municípios do Norte do país (os menos integrados) passam uma falsa ideia de que a cobertura é menor do que a encontrada.

Figura 5: Municípios integrados.

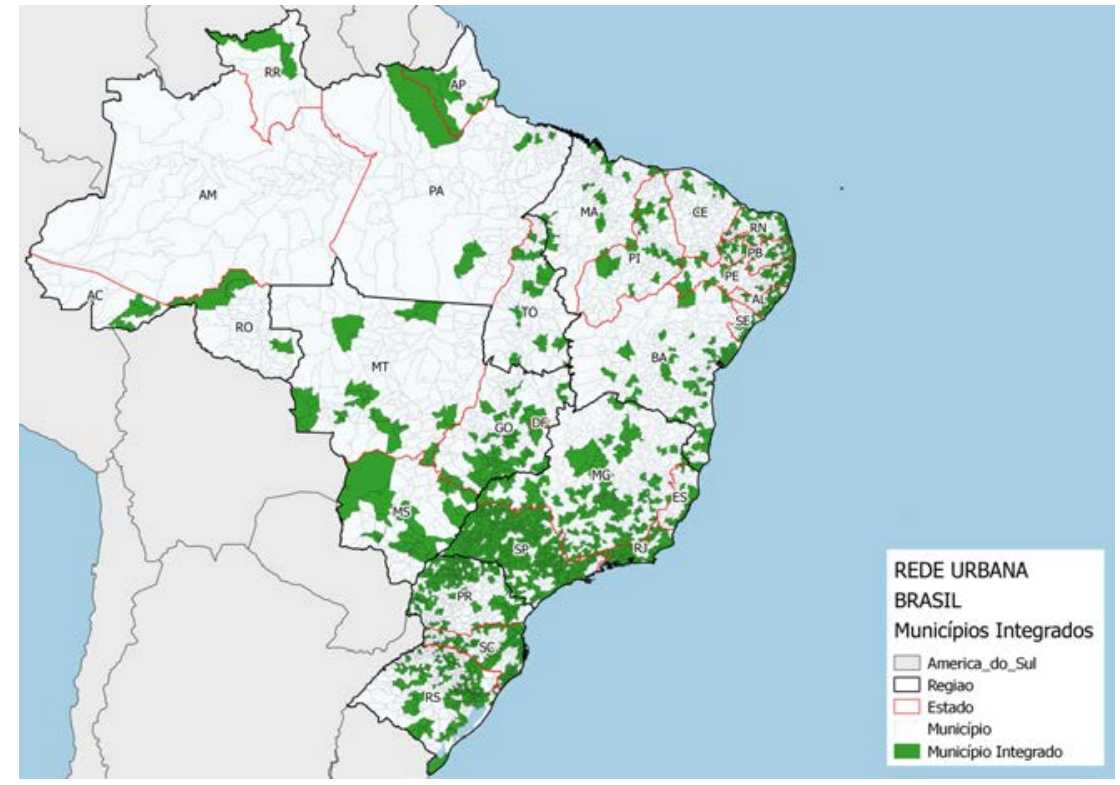

Os agrupamentos se articulam com base nos links determinados pelos movimentos pendulares considerados significativos conforme o método apresentado. A figura 6 apresenta o potencial atrator dos nós (municípios) conforme o estoque de emprego e os links (fluxos). Os links de grandes distâncias se devem à limitação dos dados de excluir movimentos que não são efetivamente pendulares. Analisando os microdados em geral eles se referem a empregos de baixa remuneração vinculados ou à construção civil ou à agricultura, tendendo, portanto, a serem empregos temporários pela demanda destas duas atividades. No agrupamento esses municípios foram excluídos. 
Figura 6: Relações entre municípios.

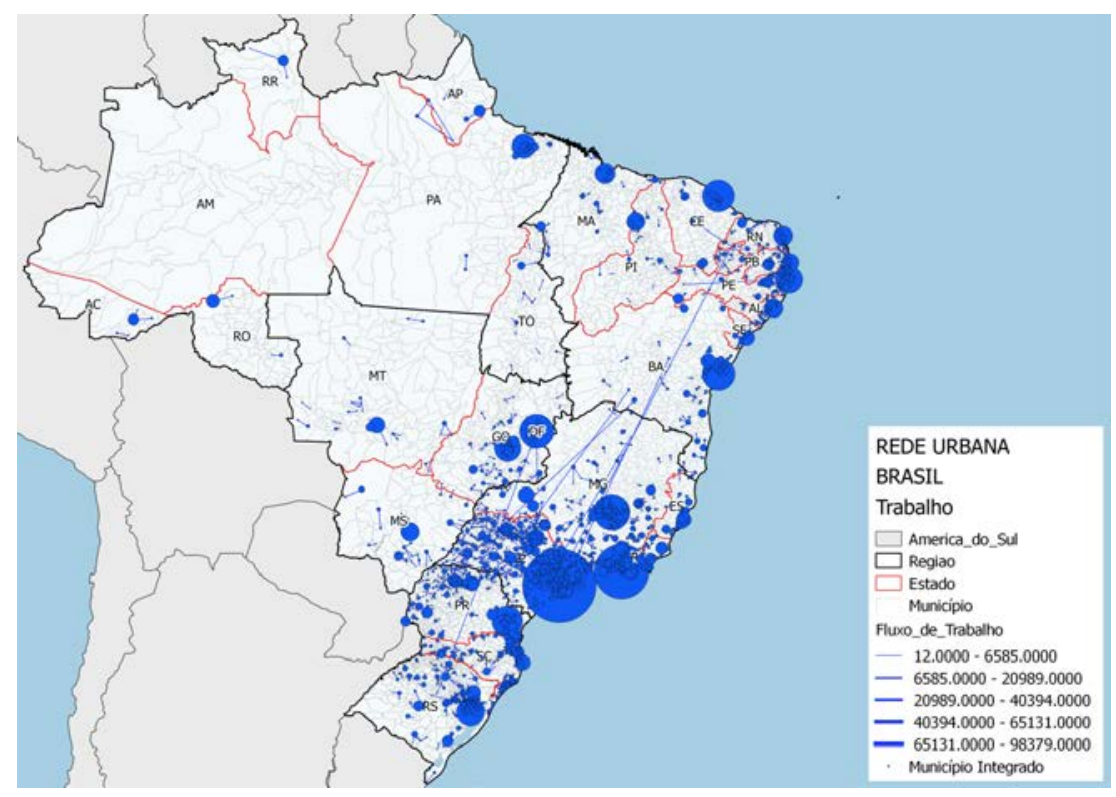

Os pontos de corte (à exceção do fluxo absoluto) geraram resultados aparentemente mais permissivos. Como foi adotada a técnica de quebras naturais, isso demonstra a fraca coesão em geral existente entre os municípios do país. Se por um lado isso revela em tese o que relativamente poderia ser considerado como relevante em termos de integração (baseada em empregos), por outro lado indica relações que podem até mesmo estar aparecendo em função do peso amostral adotado pelo IBGE e neste sentido, a representatividade do fluxo pendular intermunicipal a trabalho pode não ser tão adequado. A suposta tentativa de imparcialidade na definição do corte também pode remeter a perda de controle do entendimento do fenômeno.

\subsection{Resultados específicos e aderência às RMs}

De uma forma geral, a configuração das regiões metropolitanas "originais" (aquelas que, por serem estabelecidas antes da Constituição de 1988, ficavam a carto das diretrizes da União) possui vínculos de atração e dependência maior. Fato que não se observa com tanta intensidade na configuração atual (2010) das RMs. As situações mais criticas, conforme os critérios aqui adotados, são aquelas em que municípios da RM tem vínculos mais fortes com municípios de fora da delimitação oficial da RM. Quando eles não possuem fortes vínculos nem com municípios da RM nem com outros não parecer ser tanto problema vinculá-lo a um ou a outro.

Algumas tipologias parece ser possíveis de estabelecer a exemplo da desenvolvida por Moura. Neste caso pode-se observar se o "núcleo" da aglomeração ainda é muito atrator, ou se jpa se delineiam relações não radiais. Tendências policentrismos ainda são difíceis nos grandes centros metropolitanos, mas há relações de complementaridade maior em cidades de menor porte.

Percebe-se que os municípios essencialmente "receptores" de fluxo passam a compor a agregação de forma indireta por serem o destino de municípios "evasores".

Constatou-se também que embora o estoque de empregos se mostre ainda muito concentrado no núcleo (à exceção da RM de Vitória, com sua relação principalmente com Serra e Vila Velha), algumas configurações já demonstram fortes fluxos absolutos não radiais. $O$ exemplo mais significativo é o par Niterói-São Gonçalo, mas há exemplos significativos de fluxos absolutos, na própria RM do Rio de Janeiro (Nova Iguaçu-Belford Roxo, Belford Roxo-Duque de Caxias, Niterói-Itaboraí, Itaboraí-São Gonçalo), na RM de São Paulo (os municípios do $A B C$ entre si e a região de Osasco, Carapicuíba, Barueri, Santana de Parnaíba, Itapevi e Jandi- 
ra), na RM de Recife (Paulista-Olinda), Rm de Vitória (Serra-Cariacica e Cariacica-Vila Velha), RM de Florianópolis (São José-Palhoça), RM de Porto Alegre (Cachoeirinha-Gravataí e São Leopoldo-Novo Hamburgo, neste último caso quase indicando certa independência do núcleo), RM de Belo Horizonte (Betim-Contagem e Ibiritê-Contagem).

Destaca-se que Manaus foi a única capital de RM instituída que não apresentou fluxos significativos conforme o método, enquanto houve casos de capitais sem RM que apresentaram laços, ainda que fracos.

\section{Considerações finais}

\subsection{Limitações do método}

O método apresentado aposta na validade do uso de um único dado para refletir de forma satisfatória as relações de atratividade, complementaridade e dependência que permitem a coesão de territórios. Em verdade o interesse é validar este dado como o melhor dentre os existentes quando se escolhe apenas um. Há muitas relações que o dado não consegue captar. Observou-se, por exemplo, a pífia relação entre Santos e São Paulo, quando o senso comum indica que eles têm forte ligação. Há uma hipótese ainda a ser investigada de o método não conseguir captar bem a relação de aglomerados com seus "balneários". De fato, o perfil das cidades litorâneas do Sul e do Sudeste está mais relacionado com o uso eventual (veraneio, férias, fim de semana etc.). Dados do Censo Demográfico 2010 do IBGE apontam para percentuais altos de imóveis de uso eventual nas cidades do entorno de Santos (Bertioga: 62\%, Guarujá: 34\%, Praia Grande: 53\%; Mongaguá: 61\%; e Itanhaém 52\%). Mesmo Santos e São Vicente possuem percentuais acima da média de 5,8\% nacional. Ambas tem mais ou menos $10 \%$ de participação deste tipo de domicílio.

Parece ser necessário, ao menos para compatibilizar esses resultados com a configuração das RMs, um ponto de corte absoluto e relativo mais rígido, ou ao menos, combinado entre as três variáveis. A futura comparação com os resulta- dos presentes em IBGE (2015) pode auxiliar nos ajustes do método, bem como promover um debate mais cooperativo entre o Ipea e o IBGE.

O ponto de corte absoluto parece ser demasiado rígido, sendo quase dez vezes maior que o ponto de corte do percentil 99. Isso gera situações em que o peso relativo da variável de destino e de origem algumas vezes não sustentam fluxos próximos a 10 mil pessoas, que não é exatamente um fluxo desprezível, mesmo que relativamente baixo em relação aos empregos da origem ou no destino.

\subsection{Ajustes e aprimoramentos}

Frente a essas limitações e à observância de ajustes necessários, alguns aprimoramentos são sugeridos para o método. Um deles se refere à localização dos nós da rede. Para aprimorar a rede do ponto de vista dos nós e consequentemente dos links o ideal seria adotar o centroide da sede municipal e não o centroide do município. O centroide da sede municipal permite uma análise mais precisa das ligações e de suas distâncias ainda que seja distância em linha reta. Em um aprimoramento ainda mais elaborado poder-se-ia agregar a malha rodoviária, ferroviária e hidroviária relativa a fluxo de pessoas com isso a noção de distância seria ainda mais aperfeiçoada.

Há que se verificar se faz sentido considerarmos um elo o município com fraca atividade que envia relativamente muitos trabalhadores para vários municípios, ou seja, ele não é um elo por atratividade, mas por expulsão. É um fluxo unidirecional (é o caso de Vargem Grande Paulista, município incluído na RM de São Paulo pós 1988) não por acaso seu vínculo mais forte é com o município de onde se originou (Cotia), com o dobro de fluxo para este destino comparado com São Paulo como destino e o elo mais fraco neste tripé é com o município fora da RM (São Roque). São Roque por sua vez é um município de classificação híbrida caso se seguisse aqui a análise classificatória de Moura, Delgado e Costa (2013), pois a depender do município com que se relaciona é atrator ou expulsor. Esses ajustes às margens ou às bordas das RMs devem ser tratados com atenção. 
Percebeu-se também que a participação alta no destino não representa necessariamente que o município de origem depende do de destino para ocupar sua população, pois muitas vezes a economia do município de destino é tão incipiente que um pequeno contingente de trabalhadores do município de origem já ocupam boa parte das vagas de emprego. É necessário, portanto, que o método seja ajustado para perceber e classificar bem essas relações.

\subsection{Pesquisas futuras}

Por ser o fluxo pendular o definidor da unidade espacial mínima de análise, cabe analisar num segundo momento a condição de mobilidade destes municípios. O sistema de mobilidade incluindo a infraestrutura e os serviços de transporte destes e entre estes municípios são um limitador dessa relação. Observar possíveis gargalos é útil para identificar possíveis entraves que prejudicam o deslocamento, aumentando seus custos e por vezes inviabilizando o fluxo cotidiano e o acesso a emprego e à educação. O Censo Demográfico traz informação sobre o tempo de deslocamento, que unido à informação sobre o município ou a área de ponderação de residência e o município de trabalho pode auxiliar na identificação de estados mais críticos quanto a condições de mobilidade, sempre tomando o cuidado de entender que parte do tempo de deslocamento está relacionada à distância e não apenas à velocidade.

Aliando esses dados a características de infraestrutura e serviço de transporte (incluindo custo), condições de trânsito (quando possível) e acidentes, pode-se obter um bom quadro da situação da mobilidade. Do mesmo modo que o sistema de mobilidade urbana limita os fluxos pendulares, as infraestruturas regionais de ligação (estradas, linhas férreas, linhas aéreas, portos, rede de distribuição de energia, rede de telecomunicações) restringem ou possibilitam a relação entre as unidades espaciais mínimas de análise. Cabe, portanto, uma análise, a parte, desta dimensão, que ocorrerá num segundo momento, após a identificação dos links da rede. As classificações observadas em Moura, Delgado e Costa (2013), já adaptadas ao movimento pendular, podem na continuidade deste estudo ser usadas para se analisar o comportamento de um município com cada outro. Verificando par a par em que situações ele é receptor de pessoas, em quais é evasor e em quais e bidirecional

Definidas as unidades mínimas e os municípios isolados (aqueles que não se agregaram na aplicação do método), parte-se para a análise da relação entre essas novas unidades espaciais, neste caso não mais para configurá-las como uma agregação espacial, mas para identificar os links entre elas e sua intensidade e qualidade. O fluxo continua sendo a chave, mas desta vez, além de trabalhar com fluxos não exclusivos de pessoas, muitos deles serão viáveis apenas por meio de proxies como estoques ou fluxos indiretos. Esta constatação se deve pelo conhecimento prévio de variáveis importantes para as quais não há dados suficientemente desagregados, como o fluxo de carga em alguns modos de transporte, por exemplo.

Fluxos de energia e de comunicação também estão no escopo da análise e se necessário se observar poderão ser incluídos outros a exemplo de fluxos financeiros, de recursos naturais, de saneamento, etc. Esse mapeamento dos links da rede permitirá qualificar a relação entre as unidades mínimas para além da mera identificação de sua intensidade, auxiliando na compreensão dos motivos que fazem com que essas unidades tenham uma forte relação.

Os estudos de rede urbana e similares apresentam também como resultados indicativos de uma hierarquia urbana (entendida como hierarquia de municípios ou aglomerações), sob a ótica geral da atratividade ou importância daquele núcleo dentro da rede. Não se deve confundir com o mapeamento da rede, que está relacionada à intensidade e qualificação dos links. Neste caso trata-se do acúmulo de fluxos ou do estoque localizado em algum ponto da rede (nós). A hierarquia retrata, portanto, a importância do nó, enquanto as relações entre unidades mínimas caracterizam os links. Fechando as três componentes (delimitação, links e hierarquia), ainda poderia ser dito, para sintetizar, que o fluxo pendular determina quem são os nós, sendo portanto pré-requisito inicial para 
a representação da rede.

Para poder hierarquizar a rede em função da importância e força atrativa desses nós, é necessário compreender os fluxos recebidos e o estoque de diversas dimensões que se encontram nesses nós. Neste sentido, o investimento produtivo seja por intervenção ou incentivo estatal, seja por iniciativa privada, constitui-se causa e consequência da concentração de importância que estes nós podem ter. Mapeá-lo torna-se, portanto, tão necessário quanto identificar a situação da mobilidade urbana (para o fluxo pendular) e quanto sistematizar a infraestrutura de ligação regional (para o fluxo regional). Será necessário, evidentemente, determinar pontos de corte relativizados a cada estado para se saber quais são investimentos produtivos realmente relevantes e com potencial de fortalecer a força atrativa dessas unidades mínimas, mudando consequentemente as relações dentro da rede, ainda que não necessariamente altere sua hierarquia.

Todo este esforço não faz sentido se não for útil ao menos para algum ator. Neste sentido, ainda que possa ter utilidade para diversos atores, o foco deste trabalho é o poder público, ou os gestores e planejadores por trás da máquina pública. Há que se lembrar que todo este esforço deve ter sequência numa análise prospectiva e propositiva com a identificação de alguns cenários.

\subsection{Perspectivas}

Estudos de redes urbanas parecem ter voltado à agenda, num momento histórico em que se comemora a recente aprovação do Estatuto da Metrópole e do recentíssimo estudo do IBGE sobre áreas urbanizadas e sobre arranjos populacionais com base nos fluxos pendulares e na conturbação. A discussão, aplicação e uso em políticas de desenvolvimento dos temas territoriais na Europa e principalmente na França, mostram o quanto o Brasil está longe de aproveitar este potencial. Estudo da OCDE (2013) demonstra que há diversas políticas nacionais com cunho territorial que não são tratadas como tal. A atenção acadêmica e legal do tema deveria se refletir no interesse governamental e da sociedade de uma forma geral, em um período em que a própria Política Agrícola Comum (PAC) Europeia se aproxima do foco territorial mais do que o setorial que tradicionalmente tinha (Moyano-Estrada e Ortega, 2015)

Os vínculos intermunicipais tem se fortalecido mesmo num país de dimensões tão continentais quanto o Brasil e com boa parte do território ainda isolado em muitos aspectos para além da histórica ocupação do nosso litoral. A sanção do Estatuto da Metrópole traz explicitamente a necessidade de se definir diretrizes norteadoras para as RMs, afastando do risco eminente de tornar todo o território nacional dividido em RMs que na prática sequer conseguem ser aglomerados urbanos. A União não retomou o direito de definir as RMs, mas limitá-las.

Políticas territoriais bem intencionadas como os Territórios da Cidadania estão também passando por um processo de rediscussão do ponto de vista da identidade e coesão de seus membros. Ademais, ainda que se tenha reduzido o êxodo rural característico de outras décadas o que se avizinha são fenômenos muito mais complexos onde os limites do rural e do urbano, da cidade e do campo são mais tênues, tanto na diferenciação de serviços e infraestrutura entre esses dois espaços quanto na pluriatividade característica da contemporaneidade das famílias agricultoras. Cada vez é mais comum ter atividades típicas urbanas (e mesmo desenvolvidas em áreas urbanas) executadas por moradores das áreas formalmente rurais. E se o êxodo diminui, continua forte o contingente de trabalhadores temporários que se deslocam grandes distâncias para atuar na construção civil e na agricultura para depois retornarem às suas bases.

Esses são alguns dos desafios presentes para o planejamento e gestão regional e urbana, e entender a relação que possuem os municípios com seus vizinhos, se não resolve por si só o problema, ao menos permite que se vislumbre uma solução pensada para o conjunto do território e fiquem claras as implicações de se intervir num município sem pensar no seu entorno. 


\section{Referências bibliográficas}

ANSELIN, L. Local indicators of spatial association - LISA. Geographical Analysis, Columbus, Ohio, v.27, n.2, p.94-115, 1995.

BOUDEVILLE, J. Aménagement du territoire et polarisation. Paris : Génin, Librairies Techniques, 1972.

BURGESS, E. W. The determinants of gradients in the growth of a city, Publications, American Sociological Society, 21: 178-84, 1927.

CASADO-DÍAZ, J. M.; COOMBES, M. The delineation of 21st century local labour market areas: a critical review and a research agenda. Boletín de la asociación de geógrafos españoles, n. 57, 2011.

CASTELLO BRANCO, M. L. G. Áreas de concentração de população. In: Encontro Nacional de Produtores e Usuários de Informações Sociais, Econômicas e Territoriais, 2., 2006, Rio de Janeiro: IBGE, 2006. (Mimeo).

CASTELLO BRANCO, M. L. G. Espaços urbanos: a geografia das grandes aglomerações no Brasil. In: RIBEIRO, L. C. de Q.; JUNIOR, O. A. dos S. (Orgs.). A metrópole e a questão social brasileira. Rio de Janeiro: Revan : FASE, 2007.

CASTELLO BRANCO, M. L. G. Espaços urbanos: uma proposta para o Brasil. Rio de Janeiro: IBGE, 2003.

CASTELLO BRANCO, M.L.; PEREIRA, R.H.M.; NADALIN, V.G. Rediscutindo a delimitação das regiões metropolitanas no Brasil: um exercício a partir dos critérios da década de 1970. Texto para Discussão 1860. Rio de Janeiro: IPEA, 2013.

CHRISTALLER, W. Central places in Southern Germany. Prentice-Hall/ Englewood Cliffs, 1966. $230 p$

CORRÊA, R. L. As redes de localidades centrais nos países subdesenvolvidos. In: CORREAA, R. L. Trajetórias geográficas. Rio de Janeiro: Bertrand Brasil, 1996.

CUNHA, J. M. P.; STOCO, S.; DOTA, E. M.; NEGREIROS, R.; MIRANDA, Z. A. I. A mobilidade pendular na macrometrópole paulista: diferenciação e complementariedade socioespacial. Cad. Metrop., v. 15, n. 30, pp. 433-459, dez 2013. São Paulo: Observatório das Metrópoles, 2013. Disponível em: <http://www.scielo.br/pdf/ cm/v15n30/22369996-cm-15-30-0433.pdf>. Acesso em: 25 mar. 2015.
DAVIDOVICH, F.; LIMA, O. M. B. de. Contribuição ao estudo de aglomerações urbanas no Brasil. Revista Brasileira de Geografia, Rio de Janeiro, v.37, n.1, p.3-84, jan./mar.1975.

DE MATTOS, C. A. Globalización y metamorfosis urbana en América Latina. Quito: OLACCHI : MDMQ, 2010. (Textos Urbanos, v. 4).

DE MATTOS, C. A. Redes, nodos e cidades: transformação da metrópole latino-americana. In: RIBEIRO, L. C. Q. (Org.). Metrópoles: entre a coesão e a fragmentação, a cooperação e o conflito. São Paulo: Fundação Perseu Abramo; Rio de Janeiro: FASE - Federação de Órgãos para a Assistência Social e Educacional, 2004.

DELIMITACIÓN de las zonas metropolitanas de México. Aguascalientes [México]: Instituto $\mathrm{Na}$ cional de Estadística y Geografía - Inegi em parceria com a Secretaría de Desarrollo Social e o Consejo Nacional de Población, 2004. 110 p. Disponível em: <http://www.inegi.gob.mx/ est/contenidos/espanol/metodologias/otras/ zonas_met.pdf $>$. Acesso em: nov. 2014.

EMPLASA. Estudo da Morfologia e da Hierarquia Funcional da Rede Urbana Paulista e Regionalização do Estado de São Paulo. Documento 1 - Metodologia. São Paulo: SEP, EMPLASA, SEADE, 2011.

ESPON. European Observation Network for Territorial Development and Cohesion. ESPON Project 1.4.3: study on urban functions. Luxembourg: ESPON, 2007. Disponível em: http://goo.gl/6Uyme3

FRANÇA, K. Experiências de Governança Metropolitana Internacional: Os Casos da França, Espanha, Inglaterra e Alemanha. Texto para Discussão 1895. Brasília, 2013.

FREEMAN, A.; CHESHIRE, P. Defining and measuring metropolitan regions: a rationale. Presented at the OECD International workshop on defining and measuring metropolitan regions. Paris, 2006.

GALINDO, E.; Moura, R.; Oliveira, S.; Vasconcellos, R.; Pego, B. Contribuições ao entendimento e representação da rede urbana do Brasil (Relatório de Pesquisa). Ipea: Brasília, 2015.

GALVÃO, M. V. et al. Áreas de pesquisa para determinação de áreas metropolitanas. Revista Brasileira de Geografia, Rio de Janeiro, IBGE, ano 31, n. 4, p. 53-127, out./dez. 1969.

HARRIS, C. D.; ULLMAN, E. L. The nature of cities, Annals, American Academy of Politicaland Social Sciences, 242: 7-17, 1945. 
HOYT, $\mathrm{H}$. The structure and growth of residential neighbourhoods in American cities,Federal Housing Administration, Washington, DC, 1939.

http://www.scielo.br/pdf/cm/v15n30/2236-9996cm-15-30-0433.pdf

IBGE - Instituto Brasileiro de Geografia e Estatística. Arranjos Populacionais e Concentrações Urbanas do Brasil. Rio de Janeiro: IBGE/DEGEO, 2015. Disponível em $<\mathrm{ftp} / /$ geoftp.ibge.gov.br/organizacao_territorial/a rran-

jos_populacionais/arranjos_populacionais.pdf>. Acesso em 26 mar. 2015.

IBGE. Coordenação de Geografia. Áreas de Concentração de População. Rio de Janeiro, 2008b. (Não publicado).

IBGE. Divisão do Brasil em Regiões Funcionais Urbanas. Rio de Janeiro: IBGE/DEGEO, 1972.

IBGE. Regiões de influência das cidades 1993. Rio de Janeiro, 2000.

IBGE. Regiões de influência das cidades 2007. Rio de Janeiro, 2008a.

IBGE. Regiões de Influência das Cidades. Rio de Janeiro, 1987.

IPARDES. Redes urbanas regionais: Sul. Brasília: IPEA, 2000. (Série Caracterização e Tendências da Rede Urbana do Brasil, 6). Convênio IPEA, IBGE, UNICAMP/IE/NESUR, IPARDES.

IPEA. Configuração atual e tendências da rede urbana do Brasil. Brasília, 2002a. (Série Caracterização e Tendências da Rede Urbana do Brasil, 1). Convênio IPEA, IBGE, UNICAMP/IE/NESUR.

IPEA. Estudos básicos para a caracterização da rede urbana. Brasília, 2002b. (Série Caracterização e Tendências da Rede Urbana do Brasil, 2). Convênio IPEA, IBGE, UNICAMP/IE/NESUR.

ISARD, W. et al. Methods of regional analysis: an introduction to regional science. Cambridge, Massachusetts: M.I.T, 1960. 784 p. (Regional science studies, 4)

JARDIM, A. P. Reflexões sobre a Mobilidade Pendular. In OLIVEIRA, L. A. P.; OLIVEIRA, A. T. R. (Org.) Reflexões sobre os deslocamentos populacionais no Brasil. Estudos \& Análises: Informações Demográficas e Socioeconômicas. No 1. Instituto Brasileiro de Geografia e Estatística. Rio de Janeiro: IBGE, 2011.

JULIEN, P. Mesurer un univers urbain en expansion. Économie et Statistique, Paris: Institut
National de la Statistique et des Études Économiques - Insee, n. 336, p. 3-33, 2000. Disponível em: <http://www.insee.fr/ fr/ffc/docs_ffc/es336a.pdf>. Acesso em: nov. 2014.

KRUGMAN, P. Geography and trade. Cambridge: MIT Press, 1993.

LENCIONI, S. Referências analíticas para a discussão da metamorfose metropolitana. In.: LENCIONI, S.; VIDAL-KOPPMANN, S.; HIDALGO, R.; PEREIRA, P.C.X. (Orgs.) Transformações sócio-territoriais nas metrópoles de Buenos Aires, São Paulo e Santiago. São Paulo: FAUUSP, 2011.

MACHADO, L.O. Urbanização e mercado de trabalho na Amazônia. Cadernos do IPPUR. Rio de Janeiro, IPPUR, ano XIII, n.1, 1999, p.109138, apud Castello Branco (2003).

MANHEIN, M.L. Fundamentals of transportation systems analysis. Cambridge. The MIT Press, Cambridge, Massachusetts, 1979.

METROPOLITAN and micropolitan statistical areas main. Washington, DC: U.S. Census Bureau, 2013. Disponível em: <http://www. census.gov/population/metro/>. Acesso em: nov. 2014.

MONASTERIO, L. Indicadores de análise regional e espacial. In.: CRUZ, B.O. et al. (Org.). Economia regional e urbana: teorias e métodos com ênfase no Brasil. Capítulo 10. Brasília : Ipea, 2011. $406 \mathrm{p}$.

MONTEIRO, A. da C. Sugestões para o estudo de áreas metropolitanas. In: CONFERÊNCIA NACIONAL DE GEOGRAFIA E CARTOGRAFIA, 1., Rio de Janeiro: Comissão F/Fundação IBGE, 23-30 set. 1968. Mimeografado.

MOURA, R. et al. O metropolitano no urbano brasileiro: identificação e fronteiras. In: RIBEIRO, L. C. de Q.; SANTOS JÚNIOR, O. A. (Org.). As metrópoles e a questão social brasileira. Rio de Janeiro: Revan/Observatório das Metrópoles, 2007. p. 127-155.

MOURA, R.; DELGADO, P.R.; COSTA, M.A. Movimento pendular e políticas públicas: algumas possibilidades inspiradas numa tipologia dos municípios brasileiros. In BOUERI, R.; COSTA, M.A. (ed.) Brasil em Desenvolvimento 2013. Estado, planejamento e políticas públicas. Vol. 3, cap. 22. Instituto de Pesquisa Econômica Aplicada. Brasília: Ipea, 2013.

MOURA, R.; HOSHINO, T. A. P. Estatuto da metrópole: enfim, aprovado! Mas o que oferece 
à metropolização brasileira? Disponível em: <http://www.observatoriodasmetropoles.net/dow nload/estatuto_metropole_artigo_rosa.pdf>.

Acesso em 13 fev. 2015

OBSERVATÓRIO DAS METRÓPOLES. Níveis de integração dos municípios brasileiros em RMs, RIDEs e AUs à dinâmica da metropolização. Relatório de Pesquisa, dez. 2012, 108 p. Disponível em http://observatoriodasmetropoles. net/download/r elatorio_integracao.pdf. Acesso em $18 \mathrm{fev}$. 2013.

OCDE. Organisation de Coopération et de Développement Économiques. OECD Territorial Reviews. Competitive Cities. A New Entrepreneurial Paradigm in Spatial Development. OECD Publishing, 2007, 133p.

OCDE. Organisation de Coopération et de Développement Économiques. OECD Territorial Reviews: Brazil 2013. OECD Publishing, 224p.

OCDE. Organisation de Coopération et de Développement Économiques. Redefining "urban": a new way to measure metropolitan areas. OECD Publishing, 2012. Disponível em: <http://dx.doi.org/10.1787/9789264174108-en>. Acessado em: dez. 2012.

OJIMA, R. Fronteiras metropolitanas: um olhar a partir dos movimentos pendulares. Revista paranaense de desenvolvimento, v. 121, p. 109126, 2011.

OPENSHAW, S. The modifiable areal unit problem. Concepts and Techniques in Modern Geography (CATMOG) No.38. Norwich: Geo Books, 1983.

OPENSHAW, S.; TAYLOR, P. J. The modifiable areal unit problem. In: WRIGLEY, N.; BENNETT, R. (Ed.). Quantitative geography, a British view. London: Routledge and Kegan, 1981.

PEREIRA, R.H.M.; FURTADO, B.A. (Org.). Dinâmica Urbano-Regional - Rede Urbana e suas Interfaces. Brasília : IPEA, 2011.

PERROUX, F. L'economie du XXeme siècle. Paris: Galimard, 1949.

PRED, A. R. E TÖRNQVIST, G. (Org.). Systems of cities and information flows: Two essays, Gleerup [for] Royal University of Lund, Lund, 1973.

RESENDE, G. M. Avaliação de políticas públicas no Brasil: uma análise de seus impactos regionais. Vol. I. Rio de Janeiro: Ipea, 2014.
RESENDE, G. M.; MAGALHÃES, J. C. Disparidades do produto interno bruto (PIB) per capita no Brasil: uma análise de convergência em diferentes escalas regionais (1970- 2008). Ipea, p. 1-47, 2013. (Texto para Discussão, n. 1.833).

RIBEIRO, L. C. de Q. Hierarquização e identificação dos espaços urbanos. Rio de Janeiro: Letra Capital : Observatório das Metrópoles, 2009.

SANTOS, M. A natureza do espaço. Técnica e tempo. Razão e emoção. $3^{a}$ Ed. São Paulo: Hucitec, 1999.

SERRANO, J. M. Progresiva polarización demográfica de las aglomeraciones urbanas en España dentro de sus ámbitos provinciales. Geographicalia, n. 51, p. 29-57, 2008.

SOARES, M. T. de S. D. Critério de delimitação de áreas metropolitanas e a possibilidade de sua aplicação ao Brasil. In: CONFERÊNCIA NACIONAL DE GEOGRAFIA E CARTOGRAFIA, 1., Rio de Janeiro: Fundação IBGE/Comissão F, set., 23-30, 1968. Mimeografado.

TAAFFE, E.J.; MORRILL, R.L.; GOULD, P.R. Transport expansion in underdeveloped countries: a comparative analysis. Geographical Review, vol. 53, n. 4 (Oct., 1963), p. 503-529.

THEIL, H. The Development of International Inequality 1960 - 1985. North-Holland: Journal of Econometrics, 42, 1989, p. 145-155.

Tobler, W. R. A computer movie simulating urban growth in the Detroit region. Economic Geography 46: 234-40. 1970

WILLIAMSON, J. G. Regional Inequality and the Process of National Development: In: NEEDLEMAN, L. (ed.) Regional Analysis: Selected Readings. Penguin Books, 1968, p. 99158. Publicado originalmente em Economic Development and Cultural Change, vol. 13, 1965, p. 3-45. 